\title{
A continuum mechanics model for mechanical fatigue analysis
}

\author{
Sergio Oller *, Omar Salomón, Eugenio Oñate \\ Departamento de Resistencia de Materiales y Estructuras en la Ingeniería, Universidad Politécnica de Cataluña, \\ International Center for Numerical Methods in Engineering (CIMNE), Jordi Girona 1-3, Módulo C1 Campus Norte UPC, \\ 08034 Barcelona, Spain
}

Received 13 January 2004; received in revised form 22 July 2004; accepted 3 August 2004

\begin{abstract}
In this paper, a thermo-mechanical constitutive model for the predictions of fatigue in structures using the finite element method is formulated. The model is based on the damage mechanics of the continuous medium and allows the treatment in a unified way of coupled phenomena such as fatigue with damage, plasticity, viscosity and temperature effects. Basically it is gotten sensitive models to cyclic loads starting from classical non-linear constitutive formulations incorporating the special variable influenced by the characteristics of the cyclic load.

A formulation based on the theories of damage and plasticity is developed. The necessary modifications of these theories are outlined in order to include the fatigue phenomena. A brief description of the finite element implementation is given.

Finally, results of the performance of the proposed model are shown through the simple fatigue test and the fatigue analysis of an aluminium engine alternator support.
\end{abstract}

(c) 2004 Elsevier B.V. All rights reserved.

Keywords: Fatigue numerical analysis; Plasticity-damage constitutive model; Finite element method

\section{Introduction}

Time varying cyclic loads produce failure of structural parts for values of stress lower than those obtained in static tests. This phenomenon

\footnotetext{
* Corresponding author. Fax: +34 934011048.

E-mail addresses: oller@cimne.upc.es (S. Oller), salomon@ cimne.upc.es (O. Salomón), onate@cimne.upc.es (E. Oñate).
}

is called fatigue and it is defined more generally in the ASTM [1] code as: "the process of permanent, progressive and localized structural change which occurs to a material point subjected to strains and stresses of variable amplitudes which produces cracks which lead to total failure after a certain number of cycles".

Fatigue is the main cause of failure of machine parts in service, in mechanisms and structural 
elements functioning in aeronautics, naval and the automotive industry as well as in civil engineering structures such as bridges, buildings, etc.

The study of fatigue starts from the basic fact that it is not a phenomenon associated with the classic concept of plasticity and/or damage and that failure occurs under load conditions well below the strength limit of the material. Typically, a progressive loss of strength occurs depending on the number of stress cycles that induces local plasticity and/or damage effects. In addition, all these phenomena are usually coupled with thermal effects.

Collapses by fatigue are especially dangerous because they are unpredictable, giving no prior notification of the imminent failure: they occur suddenly and show no exterior plastic deformations. They are fragile failures which display two well separated zones: a dark polished zone showing obvious ductile cleavage which happened smoothly and a rough shinier zone where the final break is localized after surpassing the fatigue-reduced material strength.

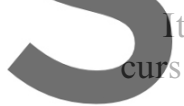

must be noted that with accompanyin

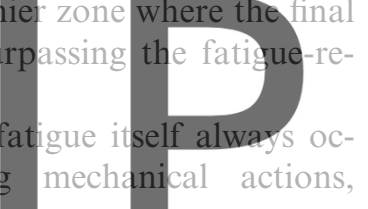

which do not seem critical by themselves but, in the end are decisive for the life of the material.

In a part subjected to cyclic loading, several conventional stages may be distinguished during a fatigue process (see Fig. 1):

- Region I, where the first micro-structural changes occur, micro-cracks form, the density of dislocations grow and later irreversible damage zones localize.

- Region II, is characterized by the macro-cracks that begin after of the coalescence of the microcracks taken place by the dominant direction induced by the mechanical problem.

- Region III, where growth of macro-cracks damage leading rapidly to total collapse.

These characteristics behaviour also can be shown in a experimental/numerical test reported in Fig. 12 that will be explained in Section 6.1.

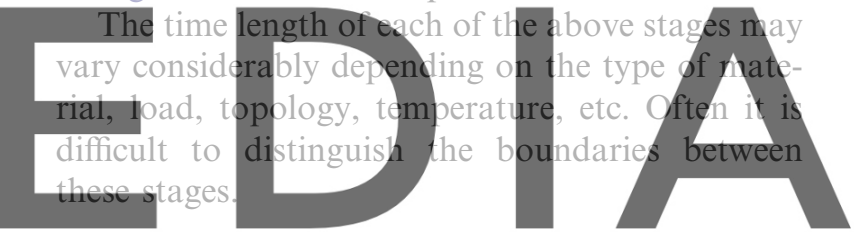

Register for free at https//www.scipedia.com to download the version without the watermark

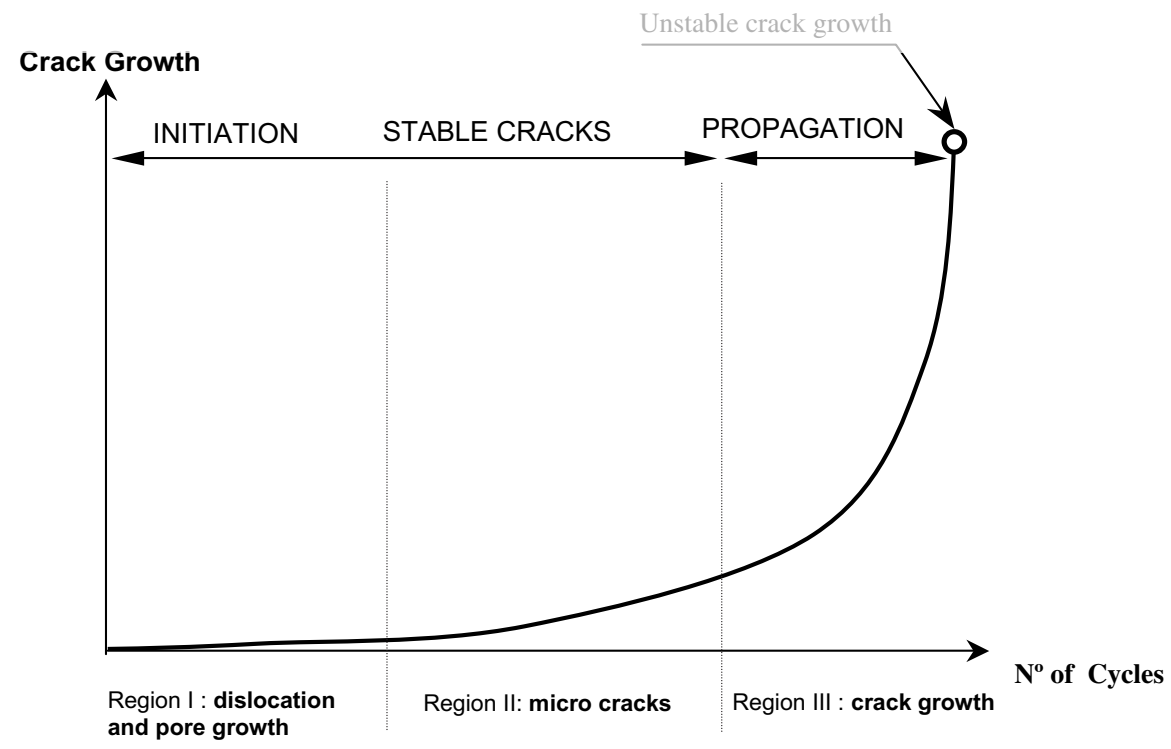

Fig. 1. Fatigue life conventional stages in the metallic materials. 


\section{Different fatigue analysis approaches}

To try to carry out a historical review of the evolution of the study of the fatigue during the last hundred seventy years would be impossible and beyond the objective of this work. For this reason a very brief presentation will be made here, even at the risk of omitting important works that have contributed to the development of this knowledge area.

The first study on fatigue was done on metallic materials around 1829 in Germany, after observing collapses of mine scaffoldings subjected to loads usually considered safe. That generated interest in the study of parts subjected to cyclic loading, which later was further fuelled by the developing railway industry.

Towards 1860, A. Wöhler, a Bavarian railway engineer, gave a decisive push to the knowledge of fatigue phenomena by performing numerous test under diverse loading conditions in order to determine the reason of prem way axles [33]. The results mell-known Stress-No cycles concept of fatigue
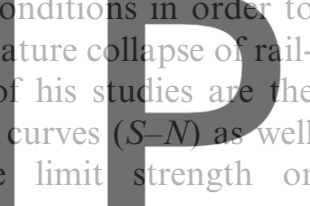

Wöhler's $S-N$ curves (see Fig. 2) are obtained Regiswereforefneeyabjhtipsoldwwidescipediaciomsto to cyclic harmonic stresses and establishing their life span measured in number of cycles. The curves depend on the level of the maximum applied stress and the ratio between the lowest and the highest stresses $\left(R=S_{\min } / S_{\max }\right)$.

Years later, around 1900, the studies set out for understanding the hardening and softening cycles of metals discovered the hysteretic strain and life curves in fatigue processes [2]. This was accomplished using constant strain amplitude cycles, thus avoiding uncontrolled stress increases which induce complex combined mechanical and fatigue phenomena.

In the 1950s, Manson [18] and Coffin [6] formulated that the plastic strain is one of the main causes of cyclic damage in metals, and proposed an experimentally derived expression relating the number of cycles to the inelastic strain.

Another point of view for studying fatigue was based on fracture mechanics. Irwin [12] related fatigue phenomena with fracture via stress intensity factors. Along the same line, years later For-

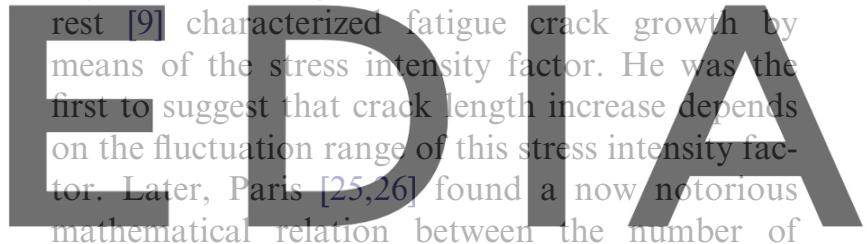

cycles and crack length, so fulfilling the original download the version is ithiout the duaternark stress states and geometries. Moreover, prediction of coupled phenomena effects present great
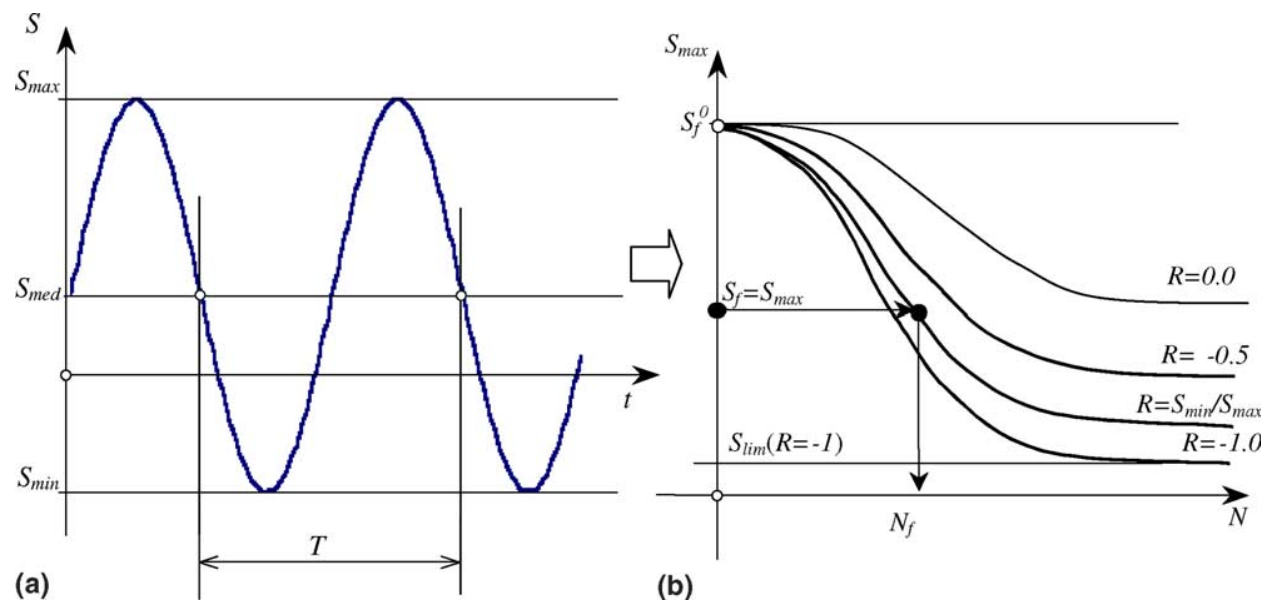

(b)

Fig. 2. (a) Stress evolution at a single point. (b) $S-N$ Wöhler's Curves. 
inconveniences when cyclic actions are superposed with uncyclic thermal or mechanical loads.

In recent years a fundamental change in focus has occurred. Chaboche [4,5] included fatigue into the general damage theory of continuum mechanics. This study was based on the hypothesis that fatigue damage is essentially of the same nature as mechanical damage and can be described via an internal variable allowing the adequate treatment of the accumulation and localization of dislocations. This internal variable relates damage to the number of cycles.

All these approaches have been formulated for periodic loads, where a dominant period may be clearly established. Little has been done in the more general case of non-periodic actions [20].

The problem becomes more complicated when plastic effects occur due to high-level loads combined with cyclic effects including additional plastic effects. Even in the absence of detectable

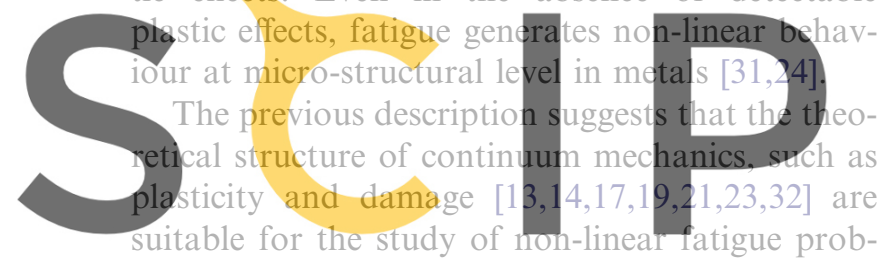

lems. From another point of view, it can be stated

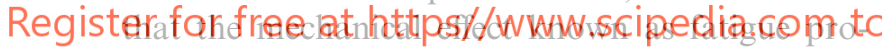

duces a loss of material strength as a function of the number of cycles, reversion index, load amplitude, etc. This loss of strength induces the material to inelastic behaviour, which may be interpreted as micro-cracking followed by crack coalescence leading to the final collapse of structural parts.

This paper presents a fatigue prediction model based on a continuum mechanics formulation accounting for coupled thermo-mechanical effects (also see [5]). Particularly the constitutive model presented here is centered in the study of the residual strength of the solids under loads that produce fatigue [30]. This model establishes the relationship between this residual strength and the yield surface, controlled by the standard internal variables (damage dissipation, plastic dissipation, etc.), plus a new internal variable of fatigue that incorporates the influence of the cyclic loads. So, by the control of the yield surface and of the dissipation energy is included in this model the concept of accumulation of "deterioration" or "damage" produced by the fatigue. This new internal variable of fatigue summarizes an idea of very general control of the behaviour and it could be applied to diverse constitutive formulations already established.

The layout of the paper is as follows. In next sections the basis of the continuum mechanics formulation is presented. Next the fatigue life prediction methodology proposed is described. Details of the finite element formulations are also given. Finally the efficiency and accuracy of the proposed model is shown in a practical example.

\section{A continuum mechanics model for fatigue analysis}

\subsection{Introduction}

A fatigue model formulated within a continuum mechanics framework overcomes most of the

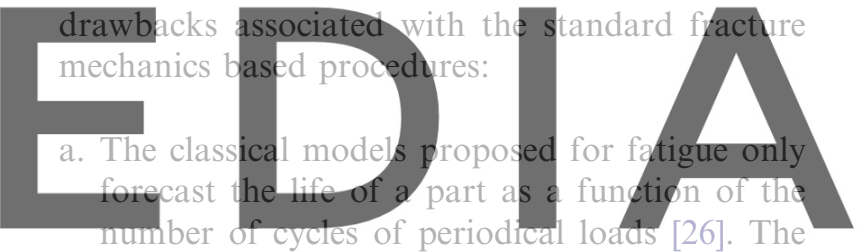

proposed model permits the introduction of downhoadstbesversion mithouth the waterimark effects of fatigue, fracture damage, plasticity. viscoelasticity, temperature, etc. This means that complex phenomena that occur in materials may be forecast for parts in service to study their safety at a given moment of their life, prior to total collapse.

b. Extending the previous idea, it must be recalled that experimental tests constitute a good tool for specific cases and for obtaining parameters, but they cannot be extended to situations more complex than those studied in the laboratory. Fracture mechanics does not offer a true solution to this problem, thus being extremely complicated to quantify the effect due to complex load conditions. Approaching the problem in a more general way, using continuum mechanics theory, makes it possible to take into account the combined effects of other factors such as thermal loads, mean stress, multi-axial stress states, plastic damage, etc. 
c. The introduction of a new internal variable related to fatigue allows treating accumulative damage without the need to formulate a complementary constitutive rule [30]. In this manner, the model proposed here is able to account for non-linear damage accumulation problems that occur when a structural part is subjected to cycles of different load amplitudes.

\subsection{Thermal and thermo-mechanical fatigue}
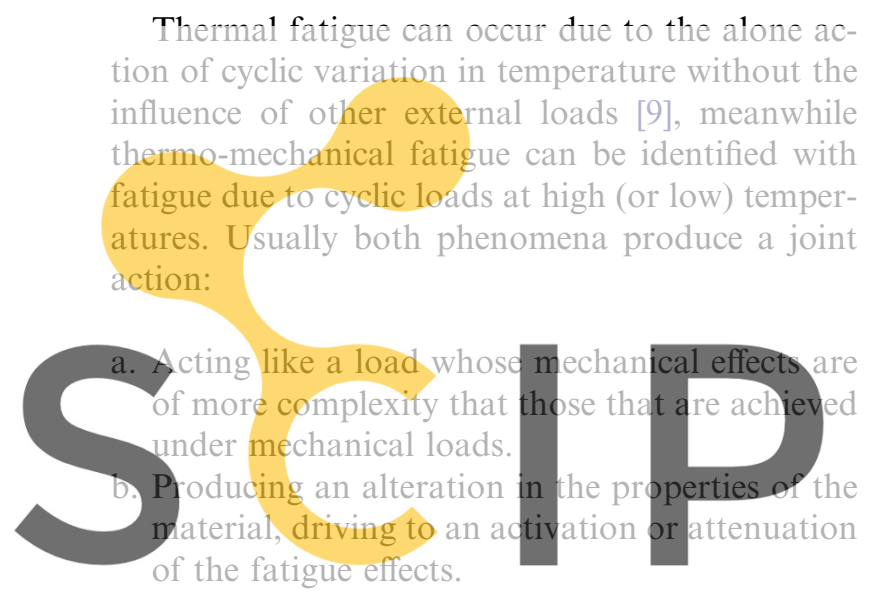

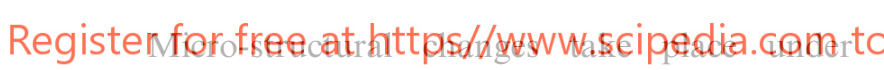
thermal alterations of the solid. In this work a macroscopic behaviour interpretation at phenomenological level is adopted. This allows studying the problem at macroscopic level by means of continuous mechanics theory. Particularly, an approach through the non-linear theories based on internal variables is adopted. More specifically, a theoretical thermo mechanical framework is developed based on the general theory of plasticity and damage that it is sensitive to the number of cycles of the thermo mechanical action [27].

\subsection{Elasto-plastic damage model. Thermo mechanical formulation}

\subsubsection{Introduction}

The inelastic theories of plasticity and/or damage can solve the problem of material behaviour beyond the elastic range and both theories allow the study of the change in strength that suffers a material point by inelastic effects throughout the yield surface control; however they are not sensitive to cyclic load effects. In this work the standard inelastic theories are modified to account for fatigue effect coupled with non-fatigue behaviour.

It is assumed that each point of the solid follows a thermo-damage-elasto-plastic constitutive law (stiffness hardening/softening) [15,16,22] with the stress evolution depending on the free strain variable and plastic and damage internal variables. The theory here presented studies the phenomena of stiffness degradation and irreversible strain accumulation through the combined effect of damage and plasticity.

\subsubsection{Thermo plastic damage model \\ Since this work is guided to mechanical prob- lems with small elastic strains, although large ine- lastic strains, the free energy additivity hypothesis is accepted $\Psi=\Psi^{\mathrm{e}}+\Psi^{\mathrm{p}}$ (see [14]). The elastic $\Psi^{\mathrm{e}}$

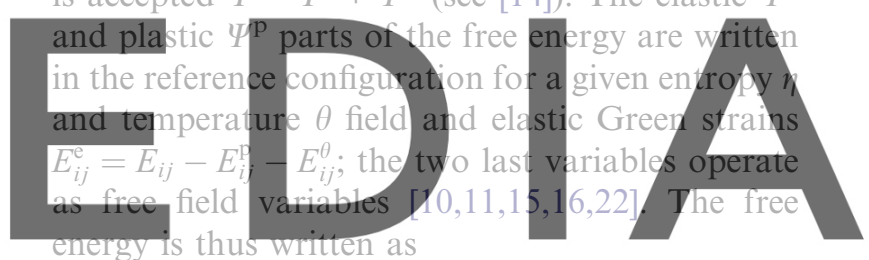

down $\Psi^{\mathrm{e}}\left(E_{\mathrm{e}}^{\mathrm{e}}\right.$ the $\left.{ }^{\theta} \Psi^{\mathrm{p}} \cdot \boldsymbol{\alpha}^{\mathrm{p}}{ }^{\theta}\right)$ without the watermark

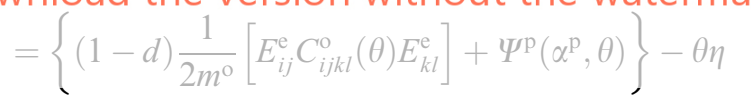

Considering the second thermodynamic law (Clausius-Duhem inequality), the thermo mechanical dissipation can be obtained as [14]

$\Xi=\frac{S_{i j} \dot{E}_{i j}^{\mathrm{p}}}{m^{\mathrm{o}}}-\frac{\partial \Psi}{\partial \alpha^{\mathrm{p}}} \dot{\alpha}^{\mathrm{p}}-\frac{\partial \Psi}{\partial d} \dot{d}-\frac{1}{\theta m^{\mathrm{o}}} q_{i} \nabla \theta \geqslant 0$

The accomplishment of this dissipation condition (Eq. (2)) demands that the expression of the stress and the entropy should be defined as (Coleman method, see [19])

$$
S_{i j}=m^{\mathrm{o}} \frac{\partial \Psi^{\mathrm{e}}}{\partial E_{i j}^{\mathrm{e}}}=(1-d) C_{i j k l}^{\mathrm{o}}(\theta)\left(E_{k l}^{\mathrm{e}}\right), \quad \eta=-\frac{\partial \Psi}{\partial \theta}
$$

Also, from the last expressions, other thermomechanical variables can be obtained as 
Constitutive tensor:

$$
C_{i j k l}^{\mathrm{s}}(d, \theta)=\frac{\partial S_{i j}}{\partial E_{k l}^{\mathrm{e}}}=m^{\mathrm{o}} \frac{\partial^{2} \Psi^{\mathrm{e}}}{\partial E_{i j}^{\mathrm{e}} \partial E_{k l}^{\mathrm{e}}}
$$

Conjugate thermal expansion coefficient:

$$
\beta_{i j}(d, \theta)=-\frac{\partial S_{i j}}{\partial \theta}=-m^{\mathrm{o}} \frac{\partial^{2} \Psi^{\mathrm{e}}}{\partial \theta \partial E_{i j}^{\mathrm{e}}}
$$

Specific heat: $\quad c_{k}=\theta \frac{\partial \eta}{\partial \theta}=-m^{\circ} \theta \frac{\partial^{2} \Psi}{\partial \theta}$

where $m^{\mathrm{o}}$ is the material density, $E_{i j}^{\mathrm{e}}, E_{i j}, E_{i j}^{\mathrm{p}}, E_{i j}^{\theta}$ are the elastic, total, plastic and thermal strain tensors, $a^{\text {ini }} \leqslant d \leqslant 1$ is the internal damage variable enclosed between its initial value $d^{\text {ini }}$ and its maximum value $1, \alpha^{\mathrm{p}}$ is a plastic internal variable, $C_{i j k l}^{\mathrm{o}}$ and $C_{i j k l}^{\mathrm{s}}$ are the original and secant constitutive tensors and $S_{i j}$ is the stress tensor for a single material point.

\subsubsection{Yield and potential plastic functions}

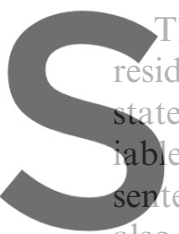

\section{The yield function $F$ summarizes}

esidual strength in function

tate, the temperature and the

allows that the elas

Iso becomes sensitive to the fatigue phenomenon.

This function and the one of plastic potential $G$

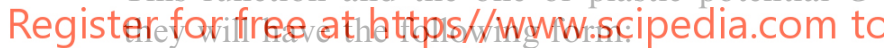

$$
\begin{aligned}
& F\left(S_{i j}, \alpha^{\mathrm{p}}, \theta\right)=f\left(S_{i j}\right)-K\left(S_{i j}, \alpha^{\mathrm{p}}, N, \theta\right) \\
& G\left(S_{i j}, \alpha^{\mathrm{p}}\right)=g\left(S_{i j}\right)=\text { cte. }
\end{aligned}
$$

where $f\left(S_{i j}\right)$ and $g\left(S_{i j}\right)$ are the uniaxial equivalent stress functions, $K\left(S_{i j}, \alpha^{\mathrm{p}}, N, \theta\right)$ is the strength threshold, $\alpha^{\mathrm{p}}=\int_{0}^{t} \dot{\alpha}^{\mathrm{p}} \mathrm{d} t$ is a plastic internal variable at current time $t[15,16,22], N$ is the number of cycles of the stress in the point of the solid and $\theta$ is the temperature.

The evolution laws for the plastic strain and the internal plastic variables are defined as

$$
\begin{aligned}
& \dot{E}_{i j}^{\mathrm{p}}=\dot{\lambda} \cdot \frac{\partial G}{\partial S_{i j}} \\
& \dot{\alpha}^{\mathrm{p}}=\dot{\lambda} \cdot H\left(S_{i j}, \alpha^{\mathrm{p}}\right)=\dot{\lambda} \cdot\left(h_{\mathrm{p}}\right)_{i j} \cdot \frac{\partial G}{\partial S_{i j}}
\end{aligned}
$$

where $\lambda$ is the consistency plastic factor and $H$ is a scalar function with tensorial arguments $[15,16,22]$ that describes the evolution of each internal variable.

\subsubsection{Threshold damage function}

Onset of damage depends on the current stress state, the internal damage variable, the temperature and in this case, like in the plasticity formulation, it also depends on the number of cycles. The thresholds damage function is defined in this case as (see $[28,19])$

$G^{\mathrm{D}}\left(S_{i j}, d, \theta\right)=\bar{S}\left(S_{i j}\right)-F^{\mathrm{D}}\left(S_{i j}, d, N, \theta\right)$

where $\bar{S}\left(S_{i j}\right)$ is the equivalent stress function in the undamaged space, $F^{\mathrm{D}}\left(S_{i j}, d, N, \theta\right)$ is the strength threshold and $d=\int_{0}^{t} \dot{d} \mathrm{~d} t$ the damage internal variable. The evolution of the damage variable is defined as

$\dot{d}=\dot{\mu} \frac{\partial G^{\mathrm{D}}}{\partial \bar{S}}$

where $\mu$ is the consistency damage factor, like of consistency plastic factor, and $G^{\mathrm{D}}$ the threshold damage function defined above.

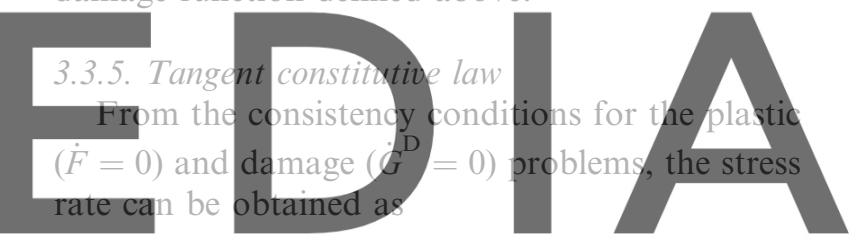

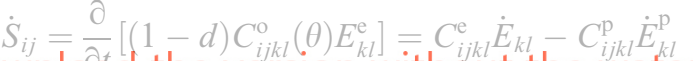
download the version without the watermark $-C_{i j k l}^{\mathrm{s}} \dot{E}_{k l}^{\theta}$, with $E_{i j}=E_{i j}^{\mathrm{e}}+E_{i j}^{\mathrm{p}}+E_{i j}^{\theta}$

where

$$
\begin{aligned}
& C_{i j k l}^{\mathrm{s}}=(1-d) C_{i j k l}^{\mathrm{o}} \\
& C_{i j k l}^{\mathrm{e}}=C_{i j k l}^{\mathrm{s}}-\frac{1}{(1-d)} \frac{\partial G^{\mathrm{D}}}{\partial \bar{S}}\left[\left(\frac{\partial \bar{S}}{\partial S_{r s}^{\mathrm{o}}}\right) C_{r s i j}^{\mathrm{o}}\right] S_{k l}
\end{aligned}
$$

Eq. (8a) can be written in the more standard form, after some algebraic manipulation, as

$\dot{S}_{i j}=C_{i j k l}^{\mathrm{ep}} \dot{E}_{k l}-C_{i j k l}^{\theta} \dot{E}_{k l}^{\theta}$

with,

$$
\begin{gathered}
C_{i j k l}^{\mathrm{ep}}=C_{i j k l}^{\mathrm{e}}-\frac{C_{i j r s}^{\mathrm{s}} \frac{\partial G}{\partial S_{r s}} \frac{\partial F}{\partial S_{m n}} C_{m n k l}^{\mathrm{e}}}{-\frac{\partial F}{\partial \alpha_{r}^{\mathrm{p}}}\left(h_{r}\right)_{t u} \frac{\partial G}{\partial S_{t u}}+\frac{\partial F}{\partial S_{m n}} C_{m n r s}^{\mathrm{s}} \frac{\partial G}{\partial S_{r s}}} \\
C_{i j k l}^{\theta}=C_{i j k l}^{\mathrm{s}}-\frac{C_{i j r s}^{\mathrm{s}} \frac{\partial G}{\partial S_{r s}}\left(\frac{\partial F}{\partial S_{m n}}-\frac{\partial F}{\partial S_{m n}} C_{m n k l}^{\mathrm{e}}\right)}{-\frac{\partial F}{\partial \alpha_{r}^{\mathrm{p}}}\left(h_{r}\right)_{t u} \frac{\partial G}{\partial S_{t u}}+\frac{\partial F}{\partial S_{m n}} C_{m n r s}^{\mathrm{s}} \frac{\partial G}{\partial S_{r s}}}
\end{gathered}
$$


In the last expressions and in the successive presentation, the material properties are assumed to be dependent on the temperature state.

\subsection{Thermo-mechanical coupling}

The heat balance equation for the coupled thermomechanical problem is deduced from the first thermodynamic law and Fourier's conduction equation $[13,14,17]$. The energy equation for thermomechanical problem can be written in the classical form as

$$
Q+J \operatorname{div}\left(k_{i} \frac{\partial \theta}{\partial x_{i}}\right)-\theta \beta_{i j} \dot{E}_{i j}^{\mathrm{e}}+D^{\mathrm{p}}-c_{k} m^{\circ} \dot{\theta}=0
$$

where $Q$ represent the caloric power, $\left(\theta \beta_{i j} \dot{E}_{i j}^{\mathrm{e}}\right)$ the thermo-elastic coupled term, $\beta_{i j}$ is the conjugate of thermal expansion coefficient, $D^{\mathrm{p}}$ the thermoplastic coupled term and $J$ is the determinant of the Jacobian matrix. Eq. (9) with the properly im-

posed boundary conditions tion of temperature influen variables. Next the form in of thermal fatigue is included frame is shown.

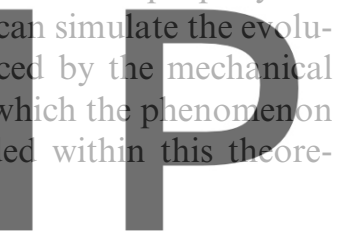

3.5. Thermo-elasto-plastic-damage model for

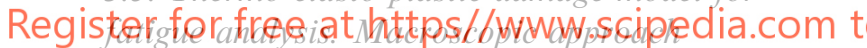

We will define next the modification of the discontinuity threshold (yield and/or damage), incorporating the number of cycles like variable. Through this modification it is gotten in this work that the classic constitutive formulations already established to simulate the non-lineal behaviours of the materials they also become sensitive to the phenomenon of the fatigue. This modification produces an "implicit evolution" of the internal plastic and/or damage variables of the non-lineal models. In addition, thermal effects in the fatigue life evolution are introduced as in the mechanical formulation, throughout an implicit internal damage variable. The non-lineal behaviour taken place by the fatigue is introduced in this procedure in implicit form, by means of the incorporation of the internal variable of fatigue that it is irreversible with the increment of the number of cycles, with the width and the average of the stresses and with the factor of reversion of the load, affecting this way the residual strength through the modification of the yield and/or damage threshold.

The effect of the number of cycles on the plastic and/or damage consistency conditions is introduced as follows:

$$
\begin{aligned}
& f\left(S_{i j}\right)-\underbrace{\bar{K}\left(S_{i j}, \alpha^{\mathrm{p}}\right) \cdot f_{\text {red }}\left(N, S_{\mathrm{med}}, R, \theta\right)}_{K\left(S_{i j}, R, N, \theta\right)}=0 \\
& \Rightarrow \underbrace{\left(\frac{f\left(S_{i j}\right)}{f_{N}\left(N, S_{\mathrm{med}}, R\right) \cdot f_{\theta}(\theta)}\right)}_{f^{\prime}\left(S_{i j}, N, R, \theta\right)}-\bar{K}\left(S_{i j}, \alpha^{\mathrm{p}}\right)=0
\end{aligned}
$$

$$
\begin{aligned}
& \bar{S}\left(S_{i j}\right)-\underbrace{\bar{F}^{\mathrm{D}}\left(S_{i j}, d\right) \cdot f_{\mathrm{red}}\left(N, S_{\mathrm{med}}, R, \theta\right)}_{F^{\mathrm{D}}\left(S_{i j}, R, N, \theta\right)}=0 \\
& \Rightarrow \underbrace{\left(\frac{\bar{S}\left(S_{i j}\right)}{f_{N}\left(N, S_{\mathrm{med}}, R\right) \cdot f_{\theta}(\theta)}\right)}-\bar{F}^{\mathrm{D}}\left(S_{i j}, d\right)=0
\end{aligned}
$$

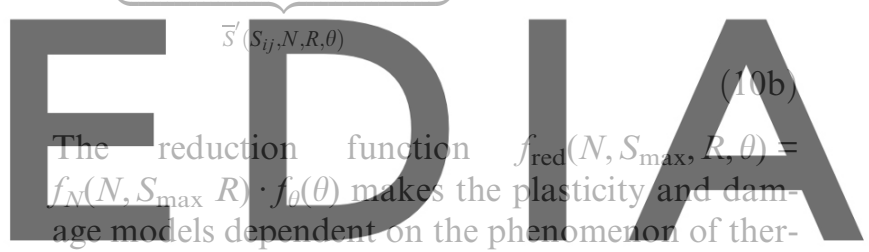

mal fatigue. In Eq. (10), $N$ is the current number of

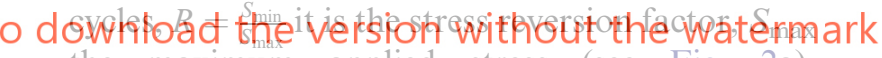

the maximum applied stress (see Fig. 2a),

$f_{N}\left(N, S_{\max }, R\right)$ is the reduction function influenced

by the number of the cycles $N$ and $f_{\theta}(\theta)$ is the thermal reduction function.

The constitutive law for the thermo-mechanical fatigue problem can be rewritten as it is shown in Eqs. (8a) and (8b), simply changing the $f$ and $\bar{S}$ functions by the normalized ones $f^{\prime}=f /\left(f_{N} \cdot f_{\theta}\right)$ and $\bar{S}^{\prime}=\bar{S} /\left(f_{N} \cdot f_{\theta}\right)$.

The coupling between damage and plasticity enforces to the definition of an only internal variable of hardening, choosing in this case the magnitude of the total of the dissipated energy for the both non-lineal processes, normalized to the unit.

$$
\begin{gathered}
\dot{q}=\Xi_{m} \cdot \mathfrak{R}\left(S_{i j}\right)=\left(\Xi^{\mathrm{p}}+\Xi^{\mathrm{d}}\right)\left[\frac{r\left(S_{i j}\right)}{g_{\mathrm{f}}}+\frac{\left(1-r\left(S_{i j}\right)\right)}{g_{\mathrm{c}}}\right], \\
r\left(S_{i j}\right)= \begin{cases}1 & \text { for pure tension } \\
0 & \text { for pure compresion }\end{cases}
\end{gathered}
$$




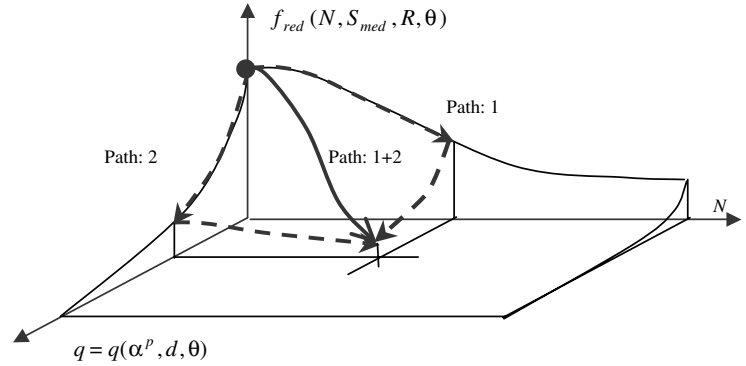

Fig. 3. Schematic view of the hyper yield-damage surface.

In this equation $\Xi^{\mathrm{p}}, \Xi^{\mathrm{d}}$ are the rates of plastic and damage energy dissipations and $g_{\mathrm{f}}, g_{\mathrm{c}}$ are the maximum energy limits that can be dissipated at a point at the end of the inelastic process. It must be observed that this definition enforces the simultaneous fulfilment of the plastic and damage consistency conditions. The mechanical process described previously allows the coupling of rate dependent or independent phenomena with the
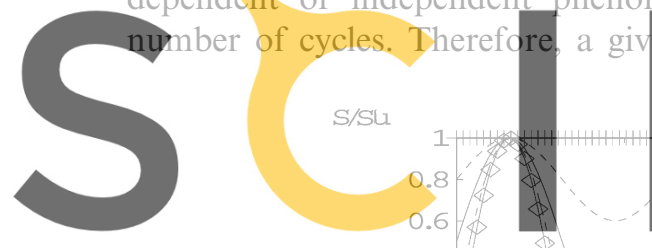

0.4

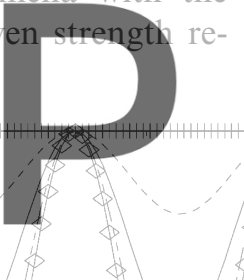

sults from the combination of two phenomena defined in independent spaces (see Fig. 3).

\section{Function of residual strength reduction for fatigue-Wöhler curve definition}

As mentioned in Section 2, Wöhler or " $S-N$ " curves are obtained from constant amplitude tests of smooth specimens cyclically loaded between a maximum $\left(S_{\max }\right)$ and a minimum stress $\left(S_{\min }\right)$ levels until failure. Typical " $S-N$ " curves for metallic materials look like as those in Fig. 2b, where it can be seen that fatigue life (for the same $S_{\max }$ applied stress) changes for different values of the ratio $R$ between $S_{\max }$ and $S_{\min }$.

\subsection{Influence of ratio $R=S_{\min } / S_{\max }$ on " $S-N$ " curves}

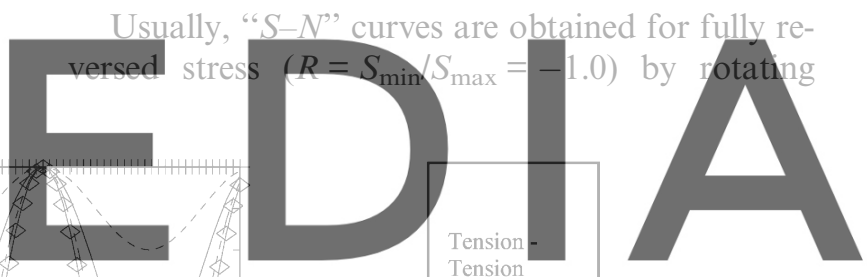

Register for free at ht€ि\$//www.scipedia.com/to download the version without the watermark

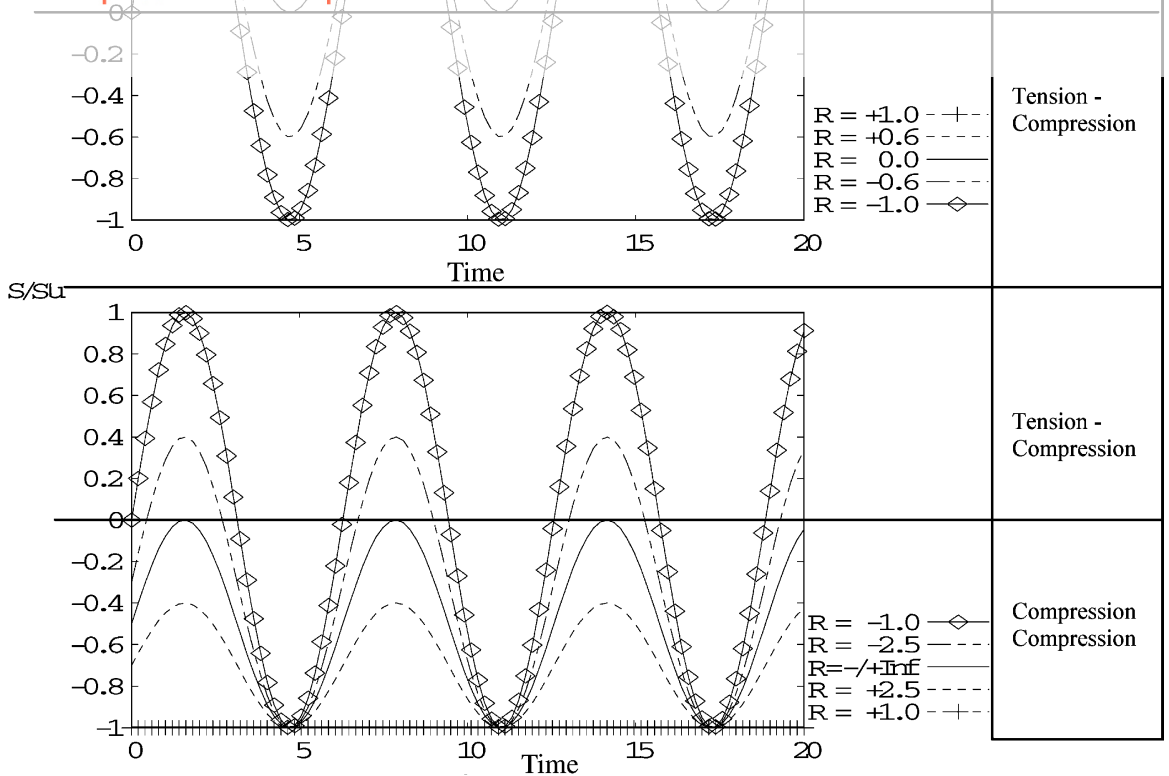

Fig. 4. Possible values for $R=S_{\min } / S_{\max }$ in case of harmonic constant amplitude function load. 
bending fatigue tests. However, this zero mean stress is not typical of real industrial components working under cyclic loads. Let us see all possible situations:

The maximum possible tension stress at a material point is $S_{\max }=S_{\mathrm{u}}\left(S_{\mathrm{u}}=P_{\max } / A_{\mathrm{o}}\right.$, ultimate stress). Lets hold $S_{\max }=S_{\mathrm{u}}$ while $S_{\min }$ changes its value from $S_{\min }=S_{\mathrm{u}}(R=+1.0)$ to $S_{\min }=0.0$ ( $R=0.0$ ), where the point is under pure tension stress. Now, lets $S_{\text {min }}$ being a compression stress, changing from $S_{\min }=0.0(R=0.0)$ to $S_{\min }=-S_{\mathrm{u}}$ $(R=-1.0)$, where the point is under a combined

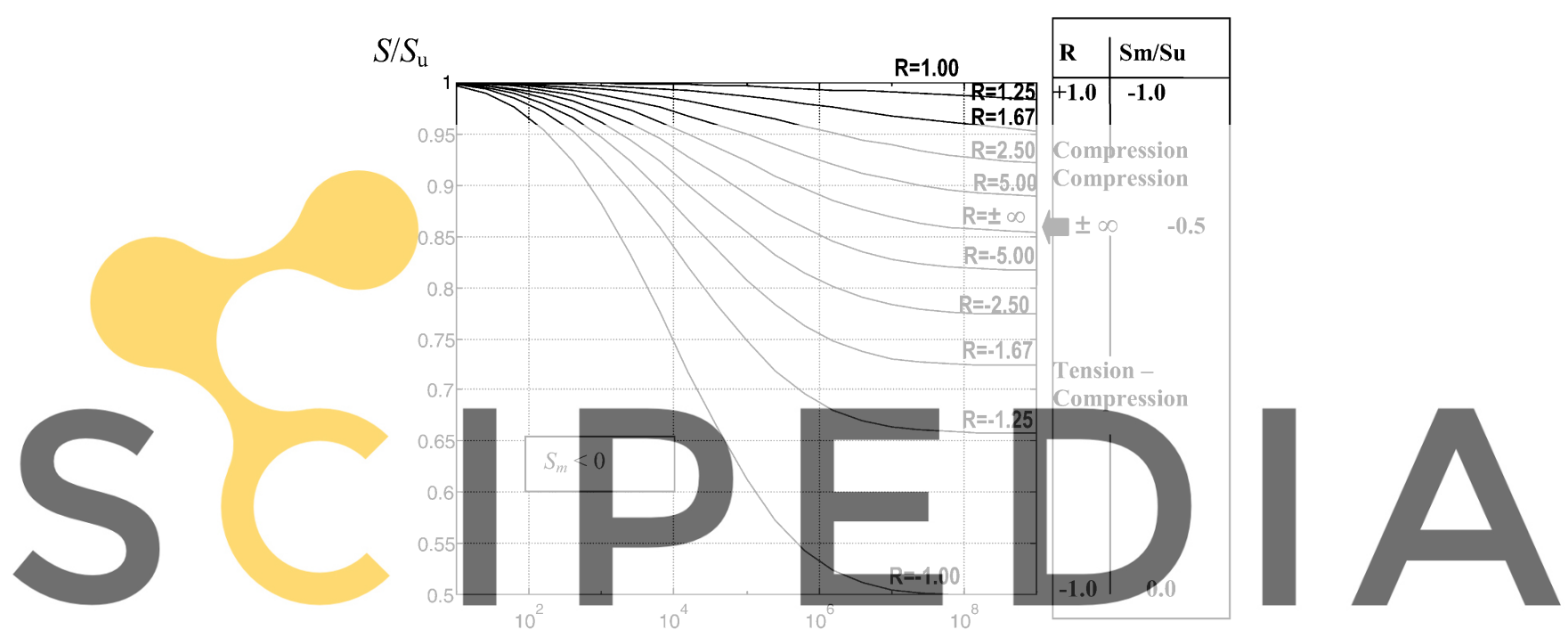

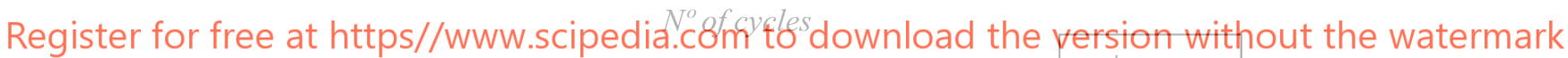

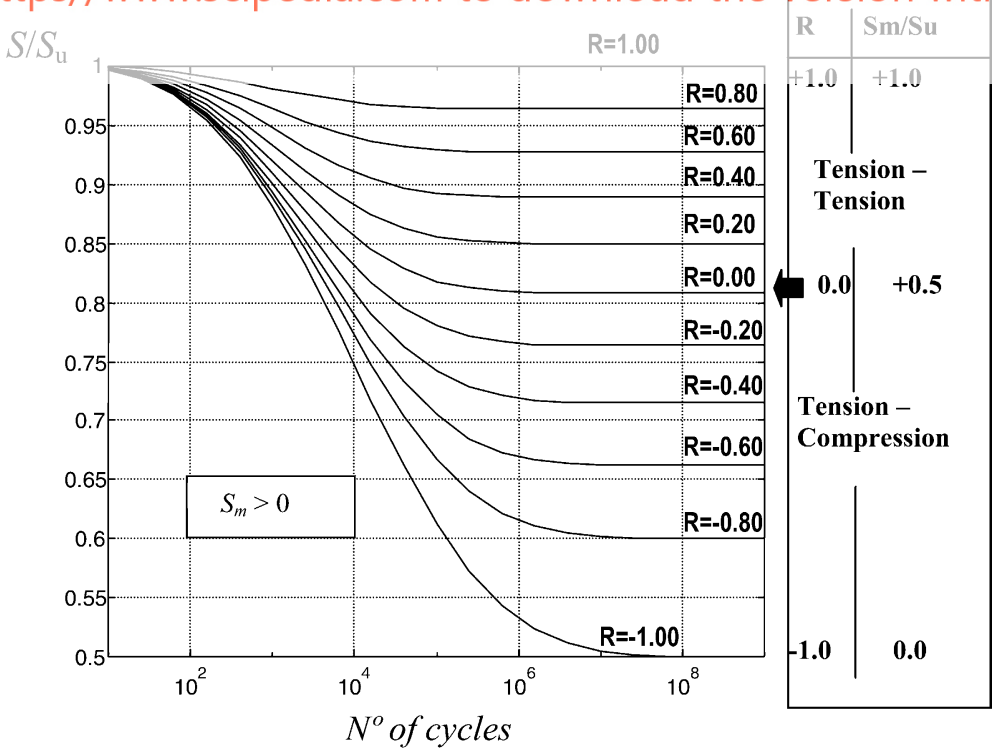

Fig. 5. Proposed $S-N$ curves for different values of $R\left(S_{\min } / S_{\max }\right)$. Parameters were chosen as follow: $\mathrm{Se}=0.5 * \mathrm{Su}, \mathrm{ALFAF}=0.0068$, BETAF $=3.35$, STHR $1=0.7$, STHR2 $=0.5$, AUXR $1=0.0133$ and AUXR2 $=0.0068$. 
tension-compression stress (see the upper part of Fig. 4). If $S_{\min }$ holds its last value, $S_{\min }=-S_{\mathrm{u}}$, and $S_{\max }$ goes down from $S_{\max }=S_{\mathrm{u}}(R=-1.0)$ to $S_{\max }=0.0(R=\infty)$, and the stress at the point is still under combined tension-compression. The possible values of $S_{\max }$ could go even lower, from $S_{\max }=0.0(R=\infty)$ to $S_{\max }=-S_{\mathrm{u}}(R=+1)$, being the point under a compression-compression stress (see the lower part of Fig. 4).

\section{2. $S-N$ curves function proposed}

Based on the actual value of the $R$ ratio and a basic value of the endurance stress $S_{\mathrm{e}}$ (for $R=-1)$ the model proposed here postulates a threshold stress $S_{\mathrm{th}}$. The meaning of $S_{\mathrm{th}}$ is that of an endurance-stress limit for a given value of $R=S_{\min } / S_{\max }$.

\section{if $\operatorname{abs}(R) \leqslant 1$}

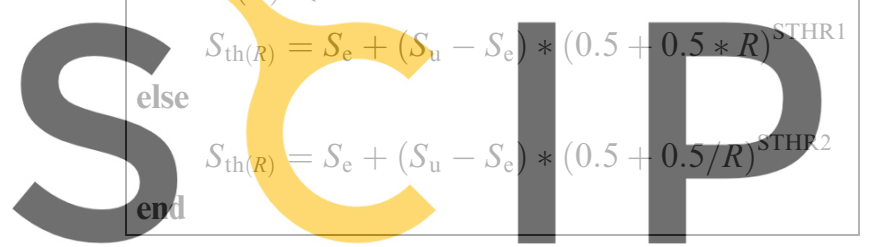

(12)

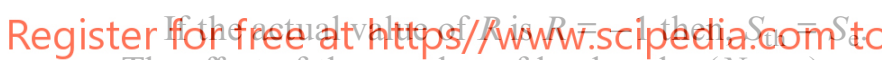
The effect of the number of load cycles $\left(N_{\text {cycles }}\right)$ on the ultimate stress $S_{u}$ for a given value of $R$ is taken into account by an exponential function,

$S_{(R, N \text { cycles })}=S_{\mathrm{th}(R)}+\left(S_{\mathrm{u}}-S_{\mathrm{th}(R)}\right) * \exp \left(-\operatorname{ALFAT}_{(R)} * \log _{10}\left(N_{\text {cyles }}\right)^{\mathrm{BETAF}}\right)$

The value of $\operatorname{ALFAT}_{(R)}$ is given by the function,

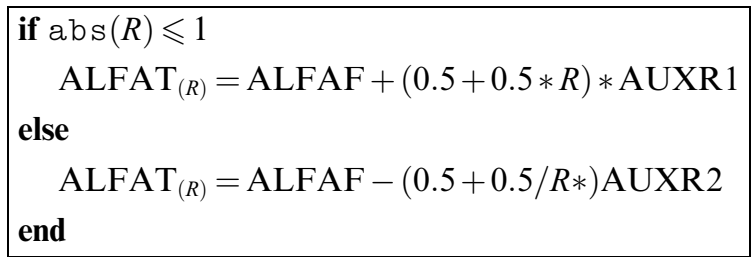

ALFAF, BETAF, STHR1, STHR2, AUXR1 and AUXR2 are material parameters that need to be adjusted according to $S-N$ experimental tests. Fig. 5 shows an example of application of these functions.

\subsection{Residual strength reduction function}

The proposed $S-N$ curves (Eqs. (12)-(14)) are fatigue life estimators for a material point with a fixed maximum stress and a given ratio $R$. If, after a number of cycles lower than the cycles to failure, the constant amplitude cyclic loads giving that maximum stress $S_{\max }$ (and ratio $R$ ) are removed, some change in $S_{\mathrm{u}}$ is expected due to accumulation of fatigue cycles.

In order to describe that variation of $S_{\mathrm{u}}$ the following function is proposed:

$f_{\text {red }(R, N \text { cycles })}=\exp \left(-B 0 *\left(\log _{10} N_{\text {cycles }} S\right)\right)^{\mathrm{BETAF} * \mathrm{BETAF}}$

BETAF is one of the parameters of Eq. (13) and $B 0$ is obtained as a function of the ratio $S_{\max } / S_{\mathrm{u}}$ and the number of cycles to failure $N_{-}$, by

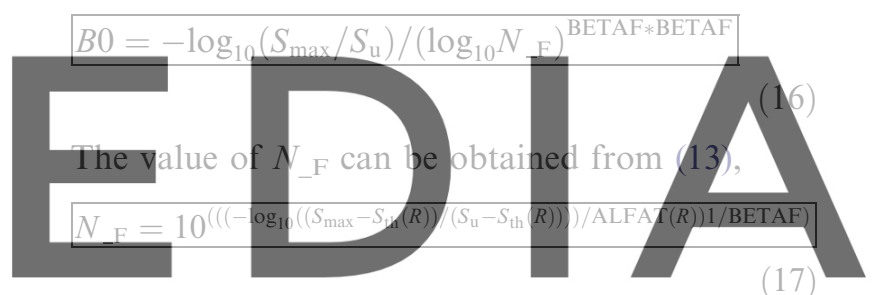

$(17)$

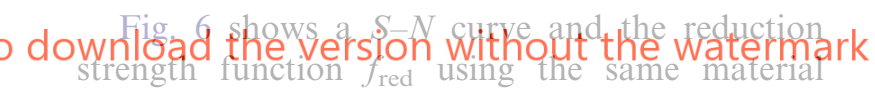
parameters of Fig. 5, a ratio $R=-1$ and a

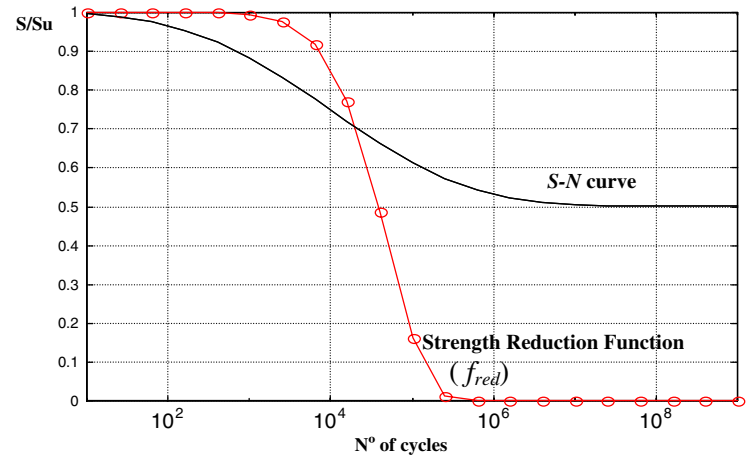

Fig. 6. Proposed strength reduction function $\left(f_{\text {red }}\right)$ obtained from $S-N$ curve for $R=-1$ and $S_{\max }=0.7 * S_{\mathrm{u}}$. The chosen parameters are: $S_{\mathrm{e}}=0.5 * S_{\mathrm{u}}$, ALFAF $=0.0068$, BETAF $=$ $3.35, \quad$ STHR $1=0.7, \quad$ STHR2 $=0.5, \quad$ AUXR $1=0.0133$ and AUXR2 $=0.0068$. 
$S_{\max }=0.7 * S_{\mathrm{u}} \cdot S_{\mathrm{u}} * f_{\text {red }}$ intersect $S-N$ curve at a $S_{\max }$ stress level.

\section{A brief review of the finite element equations}

Following the virtual work principle and the first thermodynamic law, the mechanical and thermal equilibrium equations in the referential configuration are:

$$
\left\{\begin{array}{rr}
\text { Mechanical : } & \int_{V}\left(\dot{u}_{i} \cdot m^{\mathrm{o}} \cdot \ddot{u}_{i}+S_{i j} \cdot \nabla_{i}^{\mathrm{s}} \dot{u}_{j}\right) \mathrm{d} V \\
& -\int_{V} m^{\mathrm{o}} b_{i} \dot{u}_{i} \mathrm{~d} V-\oint_{S} t_{i} \dot{u}_{i} \mathrm{~d} S=0 \\
\text { Thermal : } \quad & \int_{V} \theta \operatorname{div}\left(q_{i}\right) \mathrm{d} V+\int_{V} q_{i} \nabla \theta \mathrm{d} V \\
& -\oint_{S_{b}} \theta q_{i} n_{i} \mathrm{~d} S_{b}=0
\end{array}\right.
$$

Substituting Eq. (11) in the mechanical equation and Eq. (9) in the thermal one, and approximating the displacements field $\mathbf{u}\left(x_{i}\right) \cong \mathbf{N}^{\mathrm{u}}\left(x_{i}\right) \cdot \mathbf{U}$ and the temperature field $\theta\left(x_{i}\right) \cong \mathbf{N}^{\theta}\left(x_{i}\right) \cdot \Theta$ by the standard finite element approach [34], the following equilibrium equations are obtained:

$$
\left\{\begin{array}{l}
\mathbf{M}_{u} \cdot \ddot{\mathbf{U}}+\mathbf{f}_{u}^{\mathrm{int}}+\mathbf{M}_{u-\theta} \cdot \dot{\Theta}-\mathbf{f}_{u}^{\mathrm{ext}}=\mathbf{0} \\
\mathbf{C}_{\theta} \cdot \dot{\Theta}+\mathbf{M}_{\theta-u} \cdot \dot{\mathbf{U}}+\mathbf{K}_{\theta} \cdot \Theta+\mathbf{D}^{\mathrm{p}}-\mathbf{f}_{\theta}=0
\end{array}\right.
$$

where $\mathbf{N}^{\mathrm{u}}\left(x_{i}\right)$ and $\mathbf{N}^{\theta}\left(x_{i}\right)$ are the displacement and temperature shape functions, $\mathbf{U}$ and $\Theta$ are the nodal values of the displacements and the temperature, $\mathbf{M}_{\mathrm{u}}$ is the mass matrix, $\mathbf{f}_{u}^{\text {int }}=\left(f_{k}\right)_{u}^{\text {int }}=$ $\int_{V} S_{i j} \nabla_{i}^{S} N_{j k}^{u} \mathrm{~d} V$ is the mechanical internal forces vector that uses the stresses $S_{i j}$ evaluated by means of the constitutive model presented in Section 3 together to the life curves detailed in Section $4, \mathbf{M}_{\theta-u}$ is the thermal stiffness matrix, $\mathbf{f}_{u}^{\text {ext }}$ is the nodal force vector due to external loads, $\mathbf{C}_{\theta}$ is the caloric capacity matrix, $\mathbf{M}_{u-\theta}$ is the thermoelastic coupling matrix, $\mathbf{K}_{\theta}$ is the conductivity matrix, $\mathbf{D}^{\mathrm{p}}$ is the mechanical dispassion and $\mathbf{f}_{\theta}$ is the thermal load vector. The detailed definitions of these matrices are given in Celentano [3] and Sluzalec [29]. The solution of Eqs. (18) follows a structured staggered implicit time integration scheme. Details can be found in Celentano [3] and Sluzalec [29].

\subsection{Time advancing strategy}

A great advantage of the methodology presented above consists in the way the loading is applied. Once a state of stationary behaviour is reached in an integration point of the solid, that is to say without changes in the amplitude neither the factor of reversion of the equivalent stress, the load can be applied advancing in the number of cycles with its maximum amplitude, while the cyclic parameter of the load stays constant (amplitude or the reversion factor stress). Starting from the instant that changes the cyclic load it should be made a tracking of the load again in small fractions of time, until it is possible to reach a new stationary state. So, in a mechanical problem each load is applied in two intervals, in the following order (see Fig. 7),

(a) Tracking load (described by " $a_{i}$ " periods on Fig. 7). It is used to obtain the stress ratio $R=S_{\min } / S_{\max }$ at each integration point, following the load path during several cycles until the $R$ relationship tends to a constant value. This occurs when the following norm is satisfied:

$$
\eta=\sum_{\mathrm{GP}}\left\|\frac{R_{\mathrm{GP}}^{i+1}-R_{\mathrm{GP}}^{i}}{R_{\mathrm{GP}}^{i+1}}\right\| \rightarrow 0
$$

where $R_{\mathrm{GP}}^{i}=S_{\min } /\left.S_{\max }\right|_{\mathrm{GP}} ^{i}$ is computed at each integration point "GP" (Gauss Point) for the load increment " $i$ ".

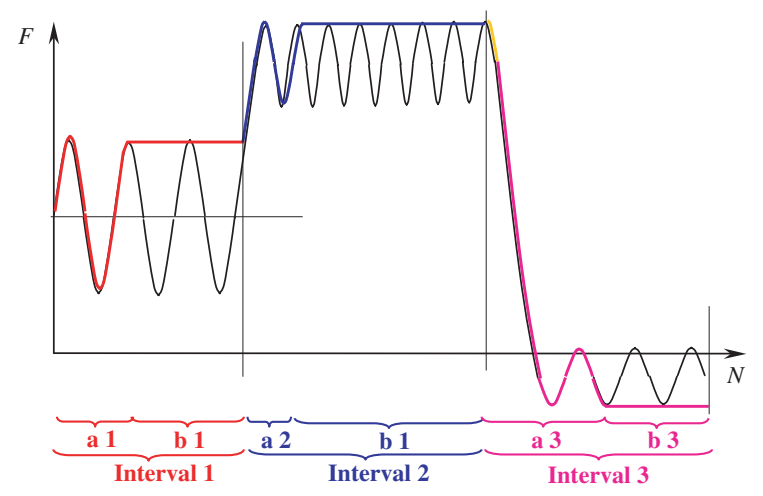

Fig. 7. Schematic time advancing loads representation. $a_{i}$ describes the tracking load domain on the $i$ interval. $b_{i}$ describes the enveloping load domain on the same $i$ interval. 
(b) Enveloping load (described by " $b_{i}$ " periods on Fig. 7). After the first "tracking load interval" $\left(a_{i}\right)$, the number of cycles $N$ is increased at each Gauss interpolation point keeping constant the maximum applied load (thick line in Fig. 7) and the $R$ stress ratio. In this new load interval, the variable is not the level of the load (kept constant), but the number of cycles.

These two-stage strategies allow a very fast advance in the time loading. A new interval with the two stages explained should be added for each change in the loading level.

\section{Crack evolution in a notched sample under fatigue effects}

Next an application of the previously constitutive model formulated to a simple piece is presented. In this example the evolution of the inner variable of damage is shown in function of the number of cycles and also the crack opening in function of the number of cycles is compared with the results obtained using the classical theory of Paris [26].

\subsection{Material properties, geometry and finite element mesh}

The symmetrical half part of the sample it is represented by 125 finite elements and 156 nodes. The standard quadrilateral 4 nodded element with 4 Gauss Points are used.

The imposed displacement $d=0.02 \times 10^{-3} \mathrm{~m}$ of amplitude and $T=1 \mathrm{~s}$ of period is applied at the top and bottom of the sample as shown in Fig. 8 . Load reversion factor of $R=-1$ and time increment $\Delta t=3 \mathrm{~s}$ are considered. Once a state of stationary behaviour is reached (see Section 5.1) the incremental load is applied advancing by cycles of $N=(t / T)^{2}$ steps (Fig. 9).

The sample is made up in steel and it is subjected to the micro crack processes by means an isotropic damage model (see Section 3.3). This steel material has a Young modulus and Poisson ratio of $E=2.01 \times 10^{5} \mathrm{MPa}, v=0.1$, while the sta-

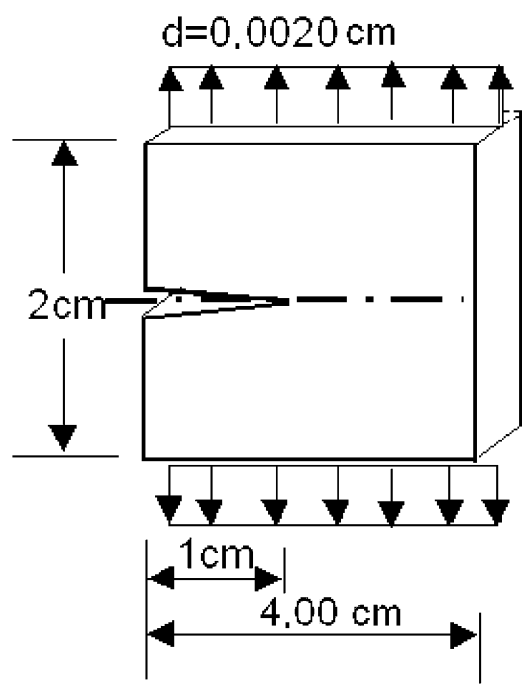

Fig. 8. Geometry and boundary constraint conditions.
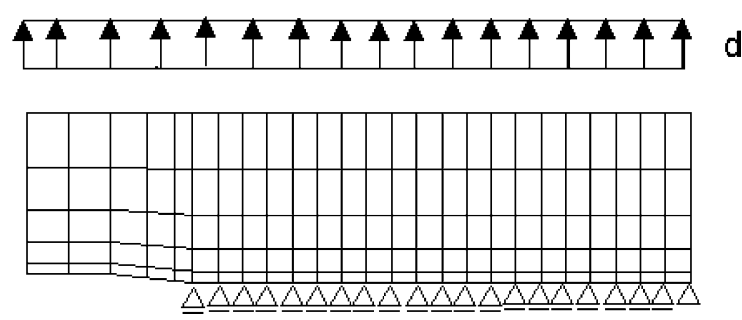

Fig. 9. Finite element mesh and boundary constraint conditions.

tic plastic-damage strength limit reaches $S_{\mathrm{u}}=838.9 \mathrm{MPa}$, and the values of the fracture and crushes energy have the following value $G_{\mathrm{f}}=G_{\mathrm{c}}=10 \mathrm{kN} / \mathrm{m}$.

\subsection{Evolution of growth cracks and strain localization}

The fatigue crack evolution produced in the notched piece subjected to tension and compression cycles of constant amplitude are shown below (applied via prescribed displacements). It is important to observe that during these cycles, the maximum initial applied stress state is lower than the elastic limit in the most stressed regions of the part ( $S=402 \mathrm{MPa})$. Nevertheless, strength depletion can be seen in the notched part, leading to a 


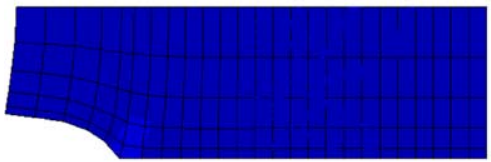

No. of cycles: $1 / 2$

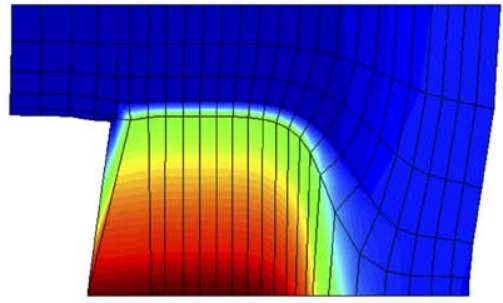

No. of cycles: 1524

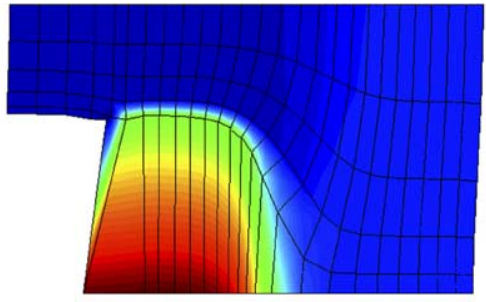

No. of cycles: 1032

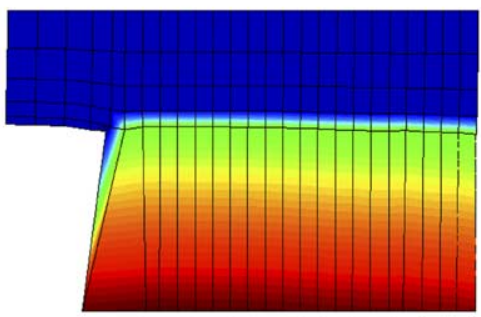

No. of cycles: 2124
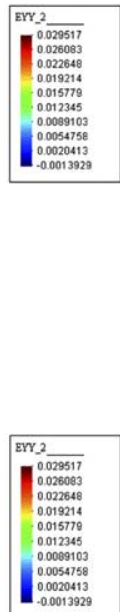

Fig. 10. Distorted mesh $\times 744$ and $E_{y y}$ strain contours for different number of cycles.

growth of cracks throughout the horizontal symmetry of the shaft.

Fig. 10 shows that the cracks evolution produced by fatigue effect. The crack opening is represented by the strain localization phenomenon produced on the shaft of the notched piece. The strength falls near to zero when the number of cycles arrives at $N_{\text {cycle }}=2124$; the sample at this moment is considered totally fractured.

\subsection{Damage evolution curves along the shaft}

Fig. 11 shows the evolution of damage at each point indicated in the notched part shown in the upper part of the figure, as a function of the number of cycles. It can be observed that the first points suffer a fast damage growth, while point number 45 start its damage growth at the final of the processes.

Below in Fig. 12, the evolution of the crack length or crack opening $a$ is presented as a function of the number of cycles. In Fig. 12, a crack opening curves evolution obtained here is shown and it is compared with the solution of the model of Paris $[25,26]$. The difference on the response ob- tained on both models, is due to the approach of Wöhler curve that has been adopted in the present work (see Section 4).

\subsection{Stress evolution curves along the shaft}

The stress evolution at each point of the crack region is indicated in the series of curves shown in Fig. 13. Note that each one of these curves corresponds to a point indicated in the figure of the previous section. Also, it can be observed that no points reached the initial damage stress limit $S_{\mathrm{u}}=838.9 \mathrm{MPa}$. Nevertheless, all the points along the axes of the part have entered in the damage state, as shown in Fig. 13.

It can also be observed that the points maintain a certain mean stress which then grows suddenly and immediately falls to zero.

Below are presented the stresses along the length for the different number of cycles. In these curves it can be observed that the stress is zero at all the points for the zero cycle level, and then increases while the number of the cycle's increases, until when reaching $N=2124$ cycles the stress is practically zeros at all the points again. Also it is 


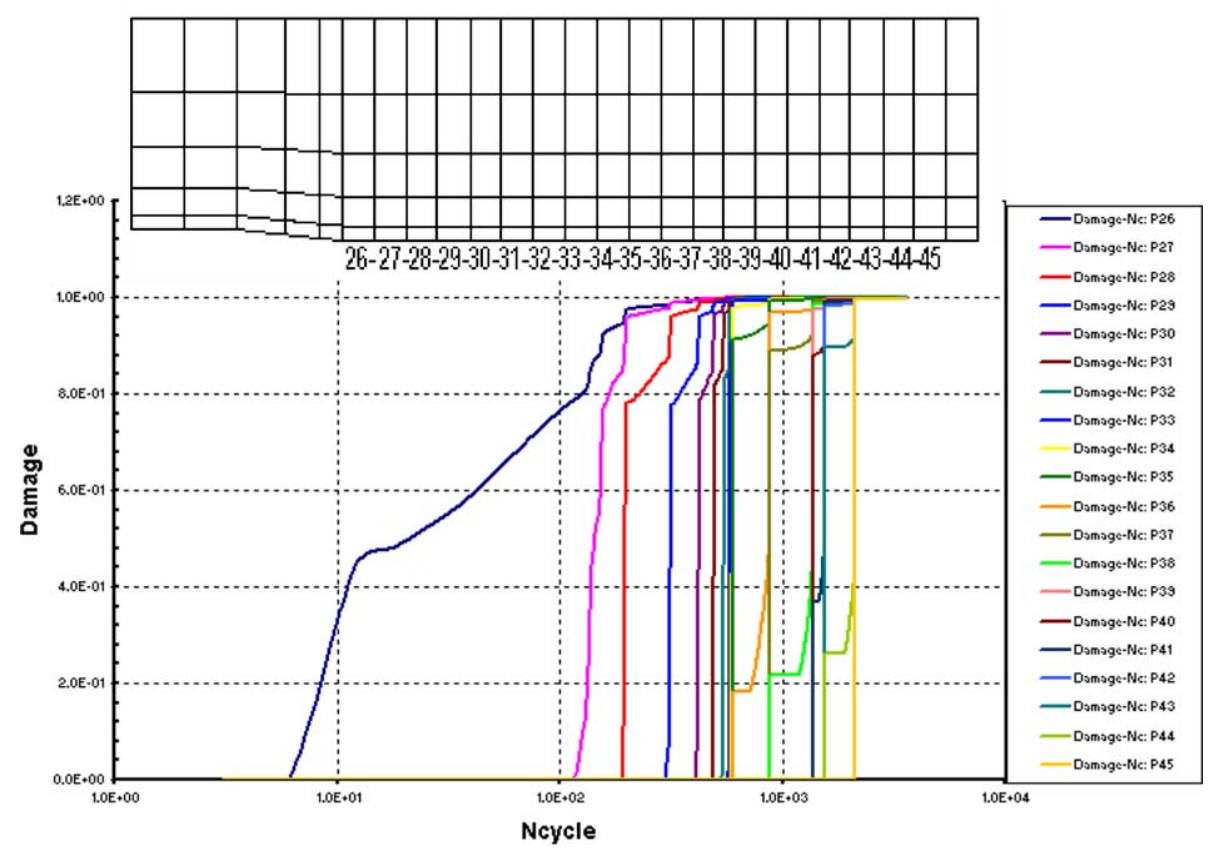

Fig. 11. Damage evolution curves along the shaft.

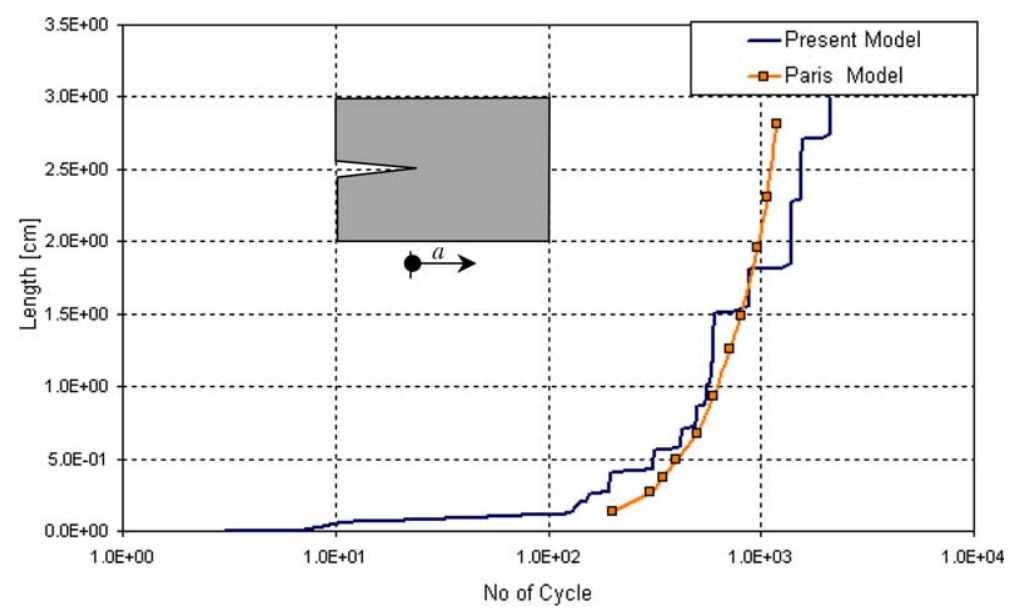

Fig. 12. Crack opening in function of the number of cycles.

important to note that there is not any point whose elastic stress reaches the initial damage threshold $S_{\mathrm{u}}=838.9 \mathrm{MPa}$, but the material is fatigued and loses its strength vanishing to zero, increasing the damage growth and the length of the cracks.

\section{Industrial validation of the proposed fatigue model}

The analytical model proposed in the previous section has been implemented into the generalpurpose thermo-mechanical finite element code 


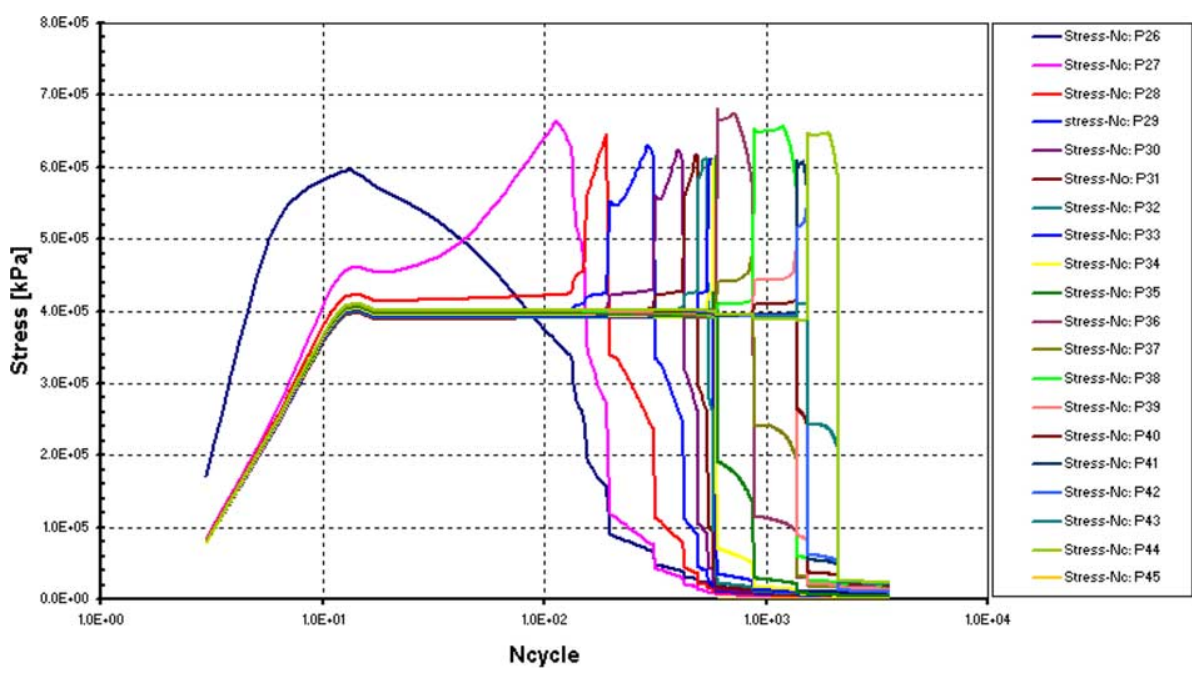

Fig. 13. Stress evolution for each point (series) along de number of the cycles.

COMET [7]. The fatigue model and its numerical implementation had been validated using real industrial components. In this section the analysis of an aluminium engine alternator support is presented. The alternator support, Fig. 14, was selected by Fonderie $2 \mathrm{~A}$ among the components of their actual production and experimentally tested by Politecnico de Torino (POLITO) in the framework of the DARCAST Project [8].

Two batches were provided: one batch of nonporous components (i.e. components with an acceptable level of porosity) and one batch of porous components; the distinction was done by the manufacturer based on radioscopy examination.
All the about 50 components submitted to fatigue testing were previously examined through radioscopic and radiographic inspection in order to classify their actual porosity level. Few components were also scanned through computed tomography to gain a more detailed analysis of the defects. The higher resolution of this last technique permitted to visualise that a scattered porosity was also present in the "non-porous" sample.

At the end of the fatigue test, the fracture surfaces were analysed both through metallographic and scanning electron microscopy to evaluate the nature and dimensions of the defects (that include pores as well as inclusions as oxide films).
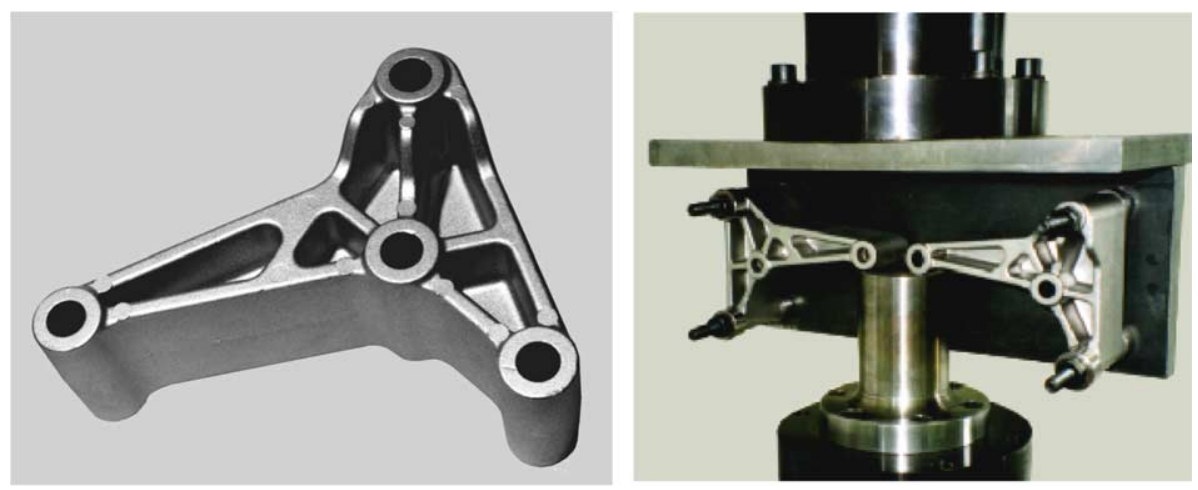

Fig. 14. Engine alternator support and equipment used for the fatigue experimental testing. 
The fatigue testing showed that for both samples (porous and non-porous) four different regions of failure could be identified. At regions of failure not highly stressed, pores of significant dimensions, oxide films and defects in the microstructure were observed on the fracture surfaces.

The difference in the fatigue limit as found for the porous and non-porous samples (the classification was made by Fonderie 2A on the basis of their standard radioscopic inspection) was observed to be statistically non-significant.

\subsection{Material characterization}

Three batches of specimens were experimentally tested, corresponding to porosity ranges $0,2,4$ (category A) according to ASTM E505 [1] standard. The porosity level was assessed through $\mathrm{X}$-ray examination.

In order to calibrate the elasto-platic constitutive model (J2) to the material (GD-AlSi8.5$\mathrm{Cu} 3.5 \mathrm{Fe}-\mathrm{UNI}$ 5075) the support was made of, a simple tension numerical test was carried out for material with porosity A0 and A2. Fig. 16 shows the numerical results (Stress-Strain curves) in comparison with those from experimental tests for material with porosity A2 (Fig. 15).

The fatigue life prediction model was also calibrated using experimental results from POLITO. Rotating bending tests $\left(R=S_{\min } / S_{\max }=-1\right)$ were run on the aluminium specimens. Tests performed

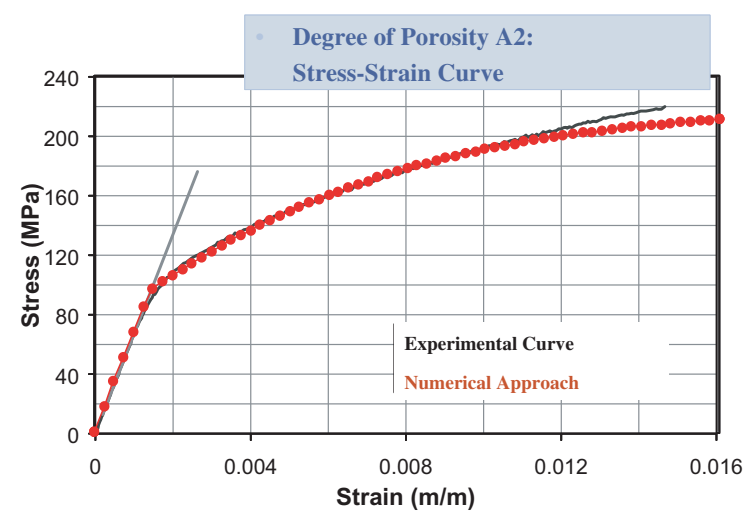

Fig. 15. Stress-Strain curve for the aluminium alloy. Experimental and numerical results. on the three batches of aluminium alloy specimens showed a great influence of porosity on the fatigue strength of the material. A significant reduction in the fatigue strength at 2 million cycles (high cycle fatigue) was found when the degree of porosity is increased from A0 to A2. The decrease was distinctly lower when the degree of porosity was further increased from A2 to A4.

Experimental results, Stress $-\mathrm{N}^{\circ}$ of cycles curves, for aluminium alloy with porosity A2 are shown in Fig. 16 and the corresponding numerical approach appears in Fig. 18. For the fatigue characterisation of the aluminium alloy, the material parameters used for the numerical test were (Fig. 17):

$$
\begin{aligned}
& S_{\mathrm{th}(R)}=S_{\mathrm{e}}+\left(S_{\mathrm{u}}-S_{\mathrm{e}}\right) *(0.5+0.5 R)^{3.5} ; \\
& \quad S_{\mathrm{e}}=0.4 S_{\mathrm{u}} ; \quad S_{\mathrm{u}}=220 \mathrm{MPa} \\
& S_{(R, N \text { cycles })}=S_{\mathrm{th}(R)}+\left(S_{\mathrm{u}}-S_{\mathrm{th}(R)}\right) \\
& \quad * \exp \left(-0.00065 * \log _{10}\left(N_{\text {cyles }}\right)^{4.55}\right)
\end{aligned}
$$

\subsection{Die cast aluminium support analysis}

Once the material was characterized for quasistatic and cyclic loading, a numerical simulation of the aluminium alternator support (Fig. 14) was done and results of the analysis were compared with those from experimental testing.

The experimental tests were done applying a minimum load of $0.5 \mathrm{kN}$ and a maximum load between 10 and $11.5 \mathrm{kN}$. For the numerical analysis these values were a minimum of $0.5 \mathrm{kN}$ and a maximum of $10.5 \mathrm{kN}$, given a mean load of $5.5 \mathrm{kN}$ and

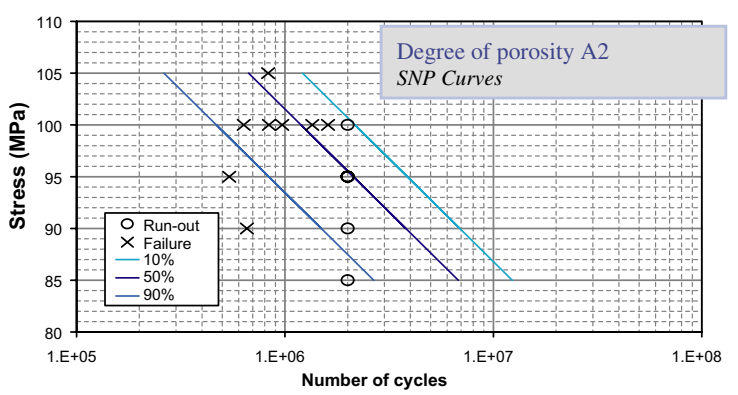

Fig. 16. Stress-Number of cycles experimental curves for the aluminium alloy. 


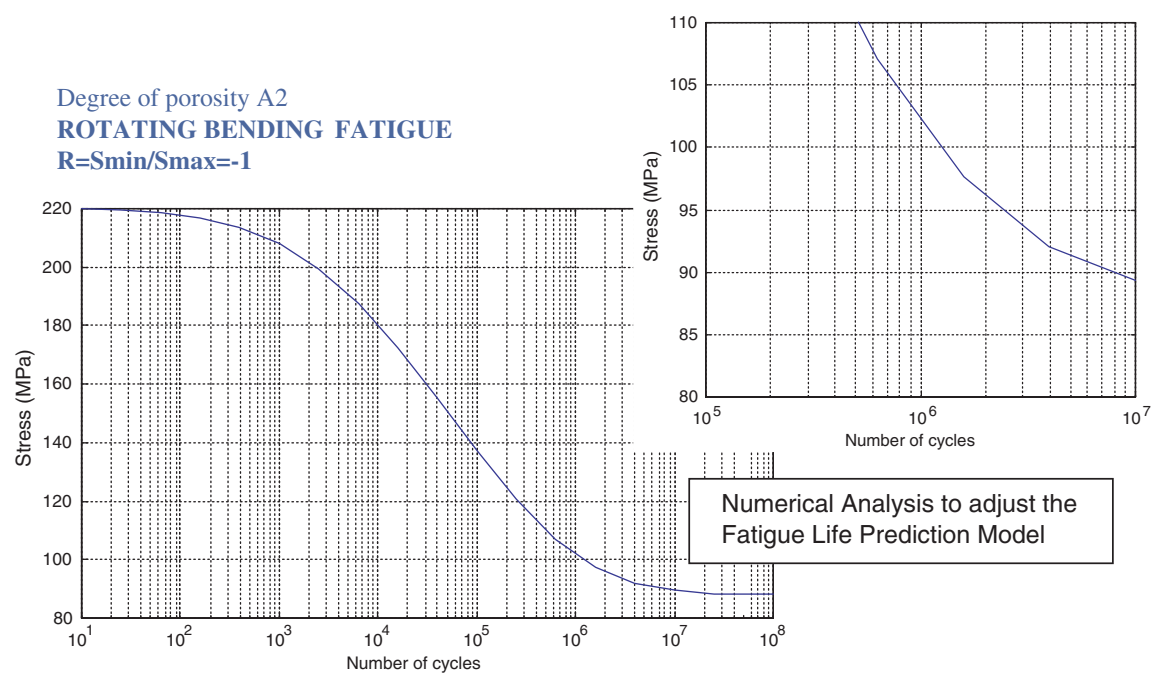

Fig. 17. Numerical approach to the $S-N$ experimental curves for the aluminium alloy.

alternating component of $5.0 \mathrm{kN}$. This cycling force was applied as a surface load as indicated in Fig. 18 on a three-dimensional model on two time intervals. Throughout the first time interval the time steps were fixed as $1 / 8$ of the period cycle. During the second interval the fatigue analysis was carried out using the maximum stresses $\left(S_{\max }\right)$ and ratios $\left(R=S_{\min } / S_{\max }\right)$ obtained on the previous interval. In this way time steps can be far larger than the used during the first interval reducing the computing time. Results presented here were obtained using a time step of $1.0 \times 10^{5}$ cycles.

Fig. 19 compares experimental regions of failure with stress distribution obtained from the numerical

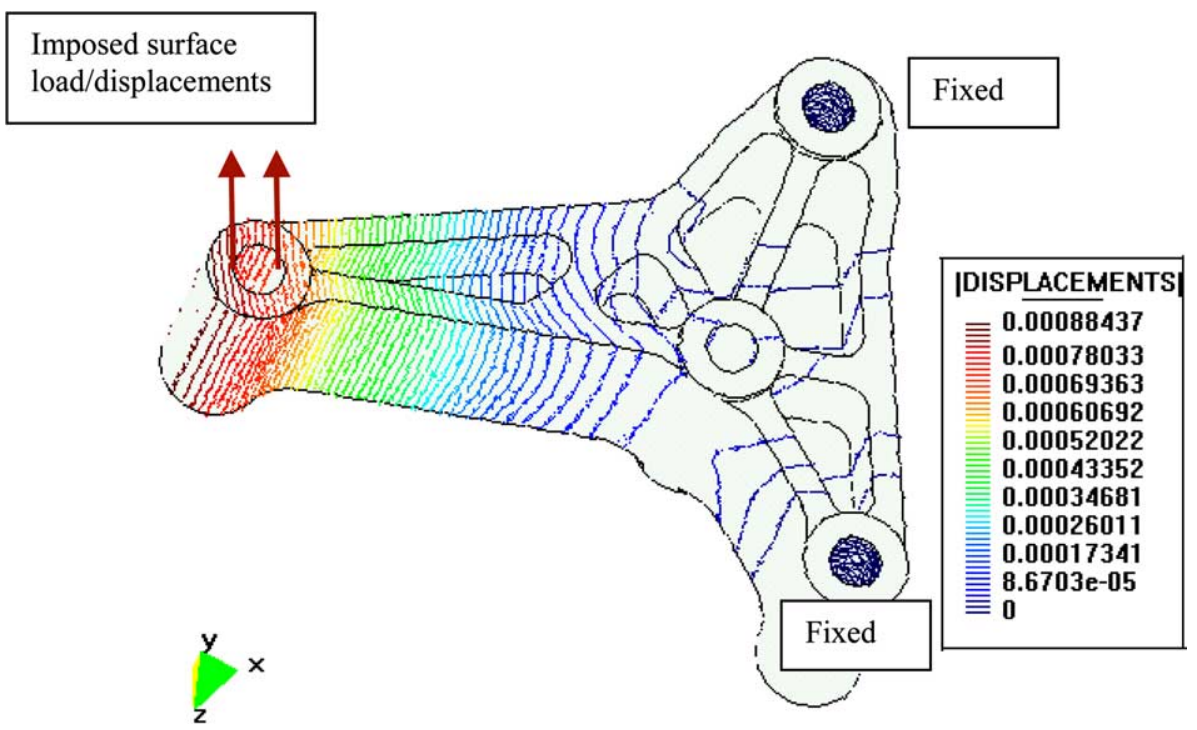

Fig. 18. Geometry, loading, boundary conditions and displacement results. 

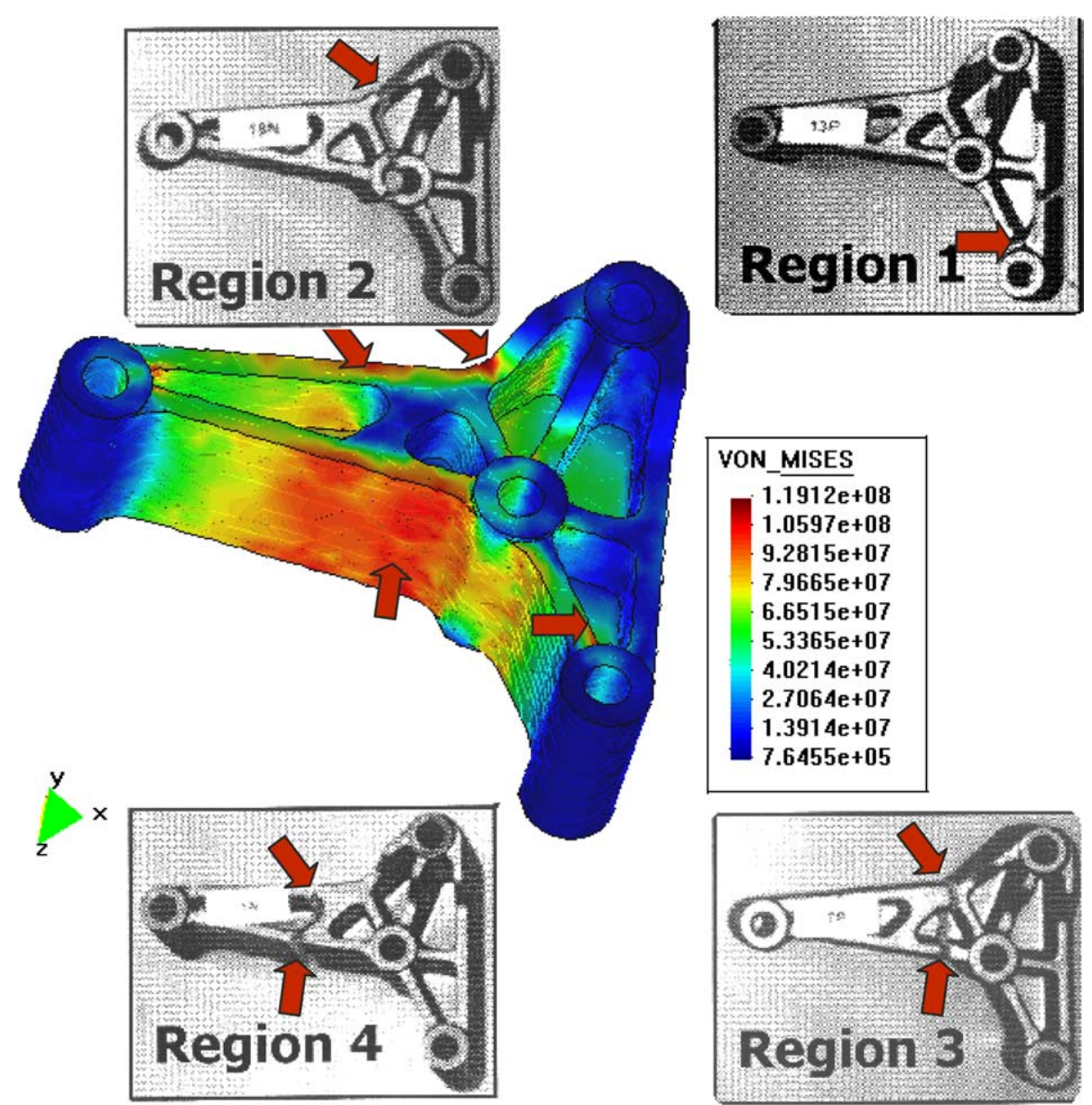

Fig. 19. Stress distribution from numerical simulation and experimental regions of failure.

simulation. Regions of failure 2, 3 and 4 are in coincidence with extended areas highly stressed.

Fig. 20 demonstrates the correlation between the damage areas due to fatigue and experimental regions of failure. Damage is observed in concordance with regions of failure 3 and 4 . Region of failure 2 (upper part) correspond to a highly compressed area what dismiss the fatigue effects. For region of failure 1 the numerical analysis only found a small area of stress concentration due to local geometry conditions.

Stress and damage index evolution during the time loading, in semi-logarithmic scale, are shown in Figs. 21 and 22 for a Gauss Point with one of the highest damage index.
Life prediction of the aluminium support according with these curves (material A2) agrees with experimental tests: Failure around 900,000 cy-

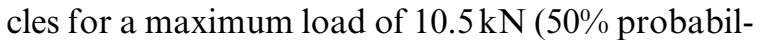
ity of survival, porous and no-porous components. No porous components indicate 'acceptable' level of porosity).

It is well known that the results from fatigue tests show a wide scattering. In the case of the aluminium support analysed, the fatigue testing identified four different regions of failure. At regions of failure not highly stressed, pores of significant dimensions, oxide films and defects in the microstructure were observed on the fracture surfaces (remark from POLITO). The uncertainty 


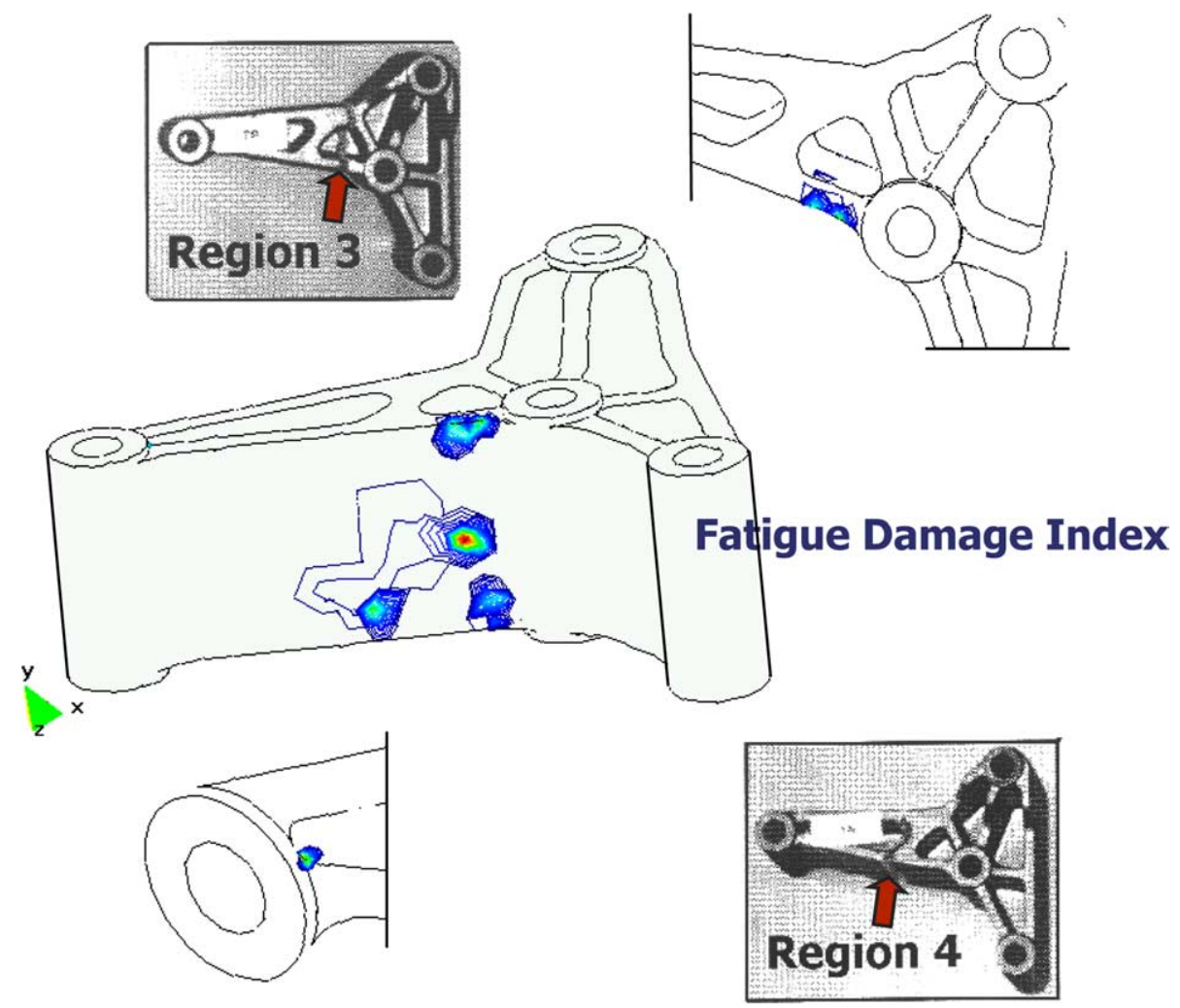

Fig. 20. Fatigue damage distribution from numerical simulation and experimental regions of failure.

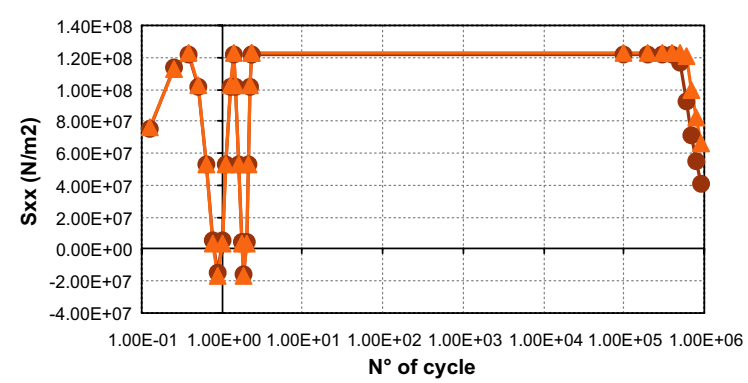

Fig. 21. Stress evolution at a Gauss Point on the damaged area.

about location of these defects, as well as errors in the estimation of material properties (variability from one specimen to another) and its effects on the probability of failure could be solved using an statistical approach. The authors are currently working on such a type of fatigue analysis.

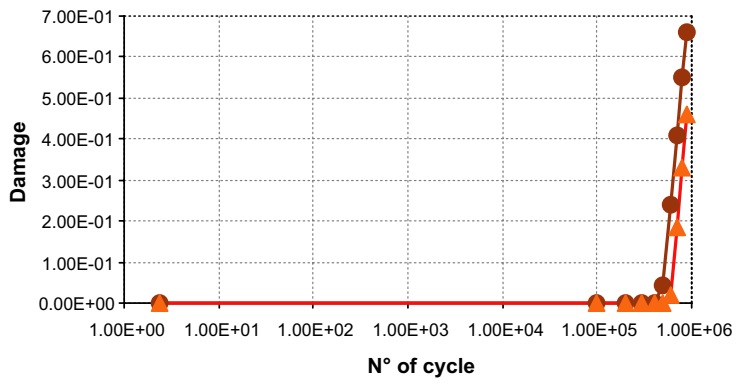

Fig. 22. Damage index evolution at a Gauss Point on the damaged area.

\section{Concluding remarks}

A powerful tool, based on continuum mechanics and the finite element method, which allows accurate predictions on fatigue behaviour of metallic components has been presented. General 
expressions for the elasto-plastic-damage constitutive equations sensitive for cyclic loads have been derived and stress-cycles and reduction strength curves functions have been proposed. The $S-N$ functions proposed depend on and are capable of dealing with any value of the ratio between minimum and maximum stress. A time advancing strategy has been formulated. This two-stage strategy (tracing load and enveloping load intervals) permits a very fast advance in the time loading.

A simple application example and aluminium industrial component have been studied to show the potential of the methodology developed which can be applied to analyse components and structures made of different materials (material parameters must be characterised for each one) and under complex cyclic loads. Comparing results from numerical mechanical analysis with those from experimental test on the industrial component, excellent relationship between highly stressed zones (as well as plastic strain zones) and regions of failure have been found. Damaged areas according the numerical analysis were observed in concordance with experimental regions of failure. Lifetime prediction of the aluminium support agrees with experimental tests.

\section{Acknowledgments}

This work has been partially funded by European Commission under the CRAFT Project BES2-5637, DARCAST, Contract BRST-CT985328 and by the Spanish government through DGICYT Project, Contract: MAT 2000-0741C02-02. This support as well as the experimental results obtained by Prof. G. Belingardi and his team at Politecnico de Torino (POLITO) is gratefully acknowledged. The authors also want to express gratitude for the supply of the industrial components by Fonderie 2A, Italy.

\section{References}

[1] ASTM Standard Definitions of Terms Relating to Fatigue Testing and Statistical Analysis of Fatigue Data.
[2] L. Bairstow, The elastic limit of iron and steel under cyclical variation of stress, Philos. Trans. Roy. Soc. Lond. (210) (1910) 35-55.

[3] D. Celentano, S. Oller, E. Oñate, A coupled thermo mechanical model for the solidification cast metals, Int. J. Solids Struct. 33 (5) (1996) 647-673.

[4] J. Chaboche, Une loi différentielle d'endommagement de fatigue avec cumulation nonlinéaire-Revue Francaise de Mécanique $\mathrm{N}^{\circ}$ (1974) 50-51.

[5] J. Chaboche, Continuum damage mechanics and its application to structural lifetime prediction, Rech. Aérosp. 4 (1987) 37-54.

[6] L. Coffin, The stability of metals under cyclic plastic strain, Trans. Am. Soc. Mech. Eng. (82) (1960) 671.

[7] COMET-Coupled Mechanical and Thermal Analysis. Data Input Manual, Version 5.0, CIMNE, Barcelona, 2002.

[8] DARCAST Enhanced Design and Manufacturing of High Resistance Casted Parts. Final Technical Report. Craft Project $\mathrm{N}^{\circ}$ : BES2-5637 funded by the European Community, 2000.

[9] P. Forrest, Fatigue of Metals, Pergamon Press, London, 1962.

[10] A. Green, P. Naghdi, A general theory of an elastic-plastic continuum, Arch. Rational Mech. Anal. 18 (1964) 251281.

[11] A. Green, P. Naghdi, A dynamical theory of interacting continua, Int. J. Engrg. Sci. 3 (1965) 231-241.

[12] G. Irwin, Analysis of stresses and strains near to the end of crack traversing a plate, Trans., ASME J. Appl. Mech. 24 (1957) 361-364.

[13] J. Lubliner, On thermodyamics foundations of non-linear solid mechanics, Int. J. Non-linear Mech. 7 (1972) 237-254.

[14] J. Lubliner, Plasticity Theory, Macmillan Publishing, New York, 1990.

[15] J. Lubliner, J. Oliver, S. Oller, E. Oñate, A plastic-damage model for concrete, Int. J. Solids Struct. 25 (3) (1989) 299 326.

[16] B. Luccioni, S. Oller, R. Danesi, Coupled plastic-damage model, Comput. Meth. Appl. Mech. Eng. 129 (1996) 8190.

[17] L. Malvern, Introduction to the Mechanics of Continuos Medium, Prentice Hall, Englewood Cliffs, NJ, 1969.

[18] S. Manson, Behaviour of metals under condition of thermal stress, Nat. Adv. Co. Aero. Report 1170 (1954).

[19] G.A. Maugin, The Thermomechanics of Plasticity and Fracture, Cambridge University Press, Cambridge, 1992.

[20] M. Miner, Cumulative damage fatigue, J. Appl. Mech. 12 (1945) 159-164.

[21] L. Neamtu, S. Oller, E. Oñate, A generalized mixing theory elasto-damage-plastic model for finite element analysis of composites. Complas V-Barcelona, 1997.

[22] S. Oller, Modelización Numérica de Materiales Friccionales-Monografía CIMNE N 3-Barcelona, 1991.

[23] S. Oller, E. Oñate, J. Miquel Canet, S. Botello, A plastic damage constitutive model for composite materials, Int. J. Solids Struct. 33 (17) (1996) 2501-2518. 
[24] C. Osgood, Fatigue Design, Pergamon Press, Oxford, 1982.

[25] P. Paris, M. Gómez, W. Anderson, Trend Eng., Univ. Wash 13 (1961) 9-14.

[26] P. Paris, F. Erdogan, A critical analysis of crack propagation laws, ASME, J. Basic Engrg. 85 (1963) 528-534.

[27] O. Salomón, S. Oller, E. Car, E. Oñate, Thermomechanical fatigue analysis based on continuum mechanics. Congreso Argentino de Mecánica Computacional, MECOM'99, Mendoza, Argentina, 1999.

[28] J. Simo, J. Ju, Strain and stress based continuum damage models-I formulation, Int. J. Solids Struct. 23 (1987) 821840.

[29] A. Sluzalec, An analysis of thermal effects of coupled thermo-plasticity in metal forming processes, Comm. Appl. Numer. Meth. 4 (1988) 675-685.
[30] A. Suero, S. Oller, Tratamiento del Fenómeno de Fatiga Mediante la Mecánica de Medios Continuos, Monograía CIMNE N 45, Barcelona, 1998.

[31] S. Suresh, Fatigue of Materials, second ed., Cambridge University Press, Cambridge, 1998.

[32] C. Trusdell, R. Toupin, The Classical Field Theories, in: S. Flugge (Ed.), Handbuch der Physik III/I, Springer-Verlag, Berlin, 1960.

[33] A. Wöhler, Versuche über die Festigkeit der Eisenbahnwagenachsen. Zeitschrift für Bauwesen 10 English summary (1867); Engineering 4 (1860) 160161.

[34] O.C. Zienkiewicz, R. Taylor, El Método los Elementos Finitos, Vol. 1, McGraw Hill-CIMNE, Barcelona, 1994. 